\title{
REVIEW
}

\section{Comparing Angiotensin II Receptor Blockers on Benefits Beyond Blood Pressure}

Helmy M. Siragy

Received: March 11, 2010 / Published online: June 1, 2010

(C) Springer Healthcare 2010

\section{ABSTRACT}

The renin-angiotensin-aldosterone system (RAAS) is one of the main regulators of blood pressure, renal hemodynamics, and volume homeostasis in normal physiology, and contributes to the development of renal and cardiovascular (CV) diseases. Therefore, pharmacologic blockade of RAAS constitutes an attractive strategy in preventing the progression of renal and $\mathrm{CV}$ diseases. This concept has been supported by clinical trials involving patients with hypertension, diabetic nephropathy, and heart failure, and those after myocardial infarction. The use of angiotensin II receptor blockers (ARBs) in clinical practice has increased over the last decade. Since their introduction in 1995, seven ARBs have been made available, with approved indications for hypertension and

Helmy M. Siragy $(\bowtie)$

Department of Medicine, Director, Hypertension Center, University of Virginia,

PO Box 801409 Charlottesville, VA 22908,

USA.

Email: hms7a@virginia.edu some with additional indications beyond blood pressure reduction. Considering that ARBs share a similar mechanism of action and exhibit similar tolerability profiles, it is assumed that a class effect exists and that they can be used interchangeably. However, pharmacologic and dosing differences exist among the various ARBs, and these differences can potentially influence their individual effectiveness. Understanding these differences has important implications when choosing an ARB for any particular condition in an individual patient, such as heart failure, stroke, and CV risk reduction (prevention of myocardial infarction). A review of the literature for existing randomized controlled trials across various ARBs clearly indicates differences within this class of agents. Ongoing clinical trials are evaluating the role of ARBs in the prevention and reduction of $\mathrm{CV}$ rates of morbidity and mortality in highrisk patients.

Keywords: atherosclerosis; atrial fibrillation; angiotensin receptor blockers; heart failure; left ventricular remodeling; myocardial infarction; renin-angiotensin-aldosterone system; renoprotection; stroke 


\section{INTRODUCTION}

Decisions surrounding antihypertensive treatment are influenced by the myriad of hypertension-induced (eg, heart failure [HF], ischemic heart or cerebrovascular disease, renal disease) and hypertension-associated (eg, type 2 diabetes [T2D] or prediabetes, atherosclerosis) conditions, with each additional cardiovascular (CV) risk factor potentiating the risk in a given patient. ${ }^{1}$ Approximately $75 \%$ of the hypertensive population is estimated to have at least one additional CV risk factor (Figure 1 ). ${ }^{2}$ With respect to $\mathrm{HF}$, regarded as the most rapidly escalating CV condition in North America, ${ }^{3}$ up to $90 \%$ of cases are preceded by hypertension ${ }^{1}$ and approximately one-third occur in conjunction with renal insufficiency. ${ }^{3}$ Overall, given that most patients with hypertension present with or develop comorbid $\mathrm{CV}$ and/or renovascular disease over their lifetime, blood pressure (BP) lowering is unlikely to be the sole goal of treatment in these patients in whom broader risk factor reduction is necessary for influencing long-term morbidity/mortality.

Angiotensin-converting enzyme inhibitors (ACEIs) and angiotensin II receptor blockers (ARBs) lower BP through blockade of the reninangiotensin-aldosterone system (RAAS), targeting the vasoconstrictive/antinatriuretic hormone angiotensin II. ${ }^{4}$ The RAAS has significance beyond hypertension given the putative role of angiotensin II in the pathogenesis of various $\mathrm{CV}$ (atherosclerosis, hypertensive left ventricular hypertrophy [LVH], HF- and atrial fibrillation $[\mathrm{AF}]$-associated remodeling) and renal diseases. ${ }^{5,6}$ The adverse effect of angiotensin II on the CV system is multifaceted (Figure 2), with the promotion of oxidative stress representing only one of several mechanisms by which it may influence the pathogenesis of target organ damage. ${ }^{6,7}$ The ARB class was introduced into clinical practice in 1995, when losartan was granted approval as an antihypertensive, and

Figure 1. Coexistence of hypertension and cardiovascular/renal comorbidities (based on the National Health and Nutrition Examination Survey [NHANES] 2003-2004). ${ }^{2} \mathrm{CAD}=$ coronary artery disease; $\mathrm{CHF}=$ congestive heart failure; $\mathrm{CKD}=$ chronic kidney disease; $\mathrm{Dys}=$ dyslipidemia $; \mathrm{Met} S=$ cardiometabolic syndrome; $\mathrm{PAD}=$ peripheral arterial disease.

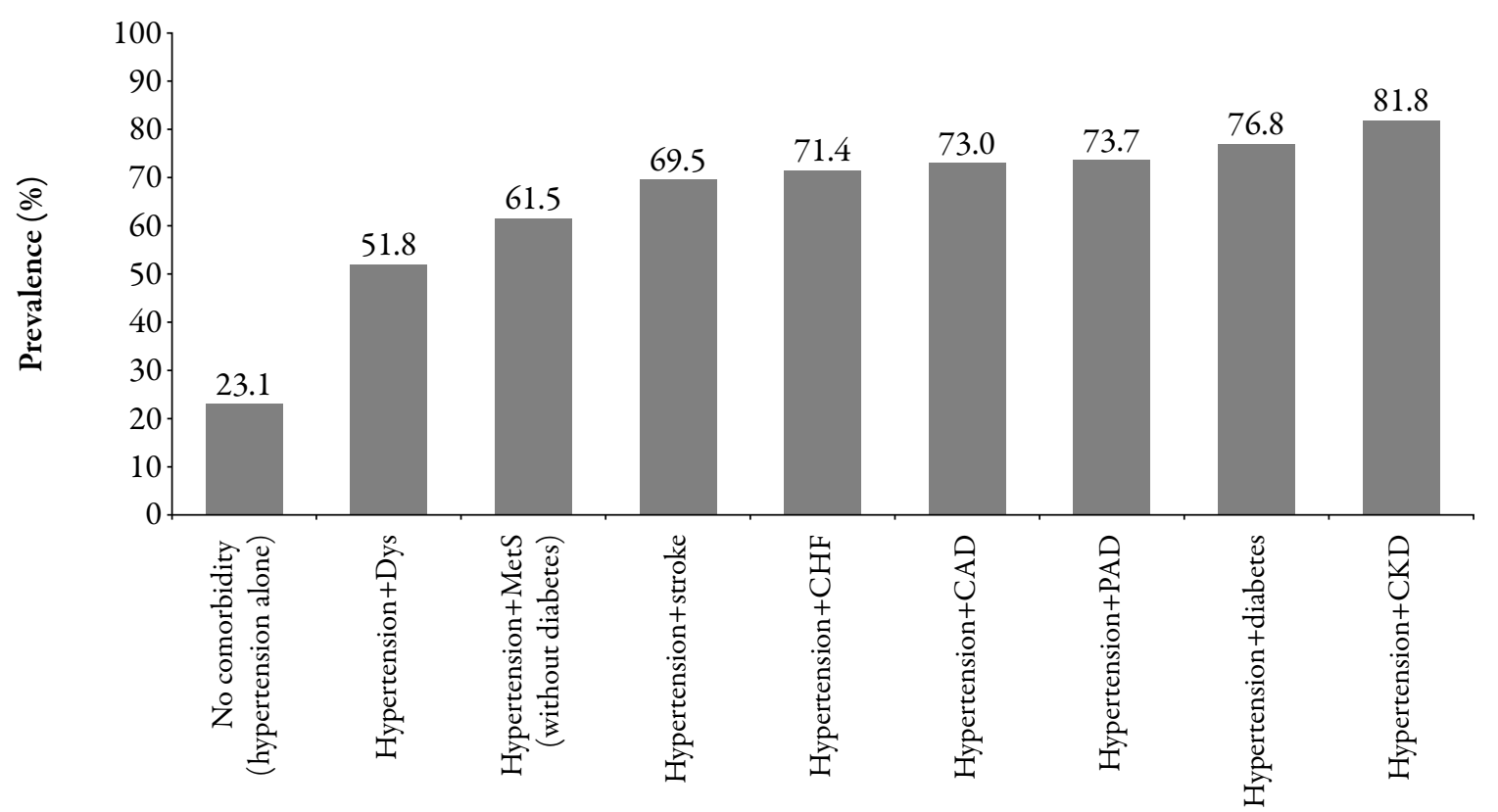


includes a total of seven agents approved for the treatment of hypertension (and, in some cases, for additional indications) (Table 1). ${ }^{8-14}$ A number of meta-analyses have calculated risk reductions for the ARB class of agents in areas outside of hypertension and, when taken together, suggest favorable effects in terms of preventing stroke and improving renal function and left ventricular (LV) mass, an uncertain risk/benefit profile in LV dysfunction and $\mathrm{HF}$, and a potential increased risk for myocardial infarction (MI) in non-HF patients. ${ }^{15-22}$ Although conducting meta-analyses that capture multiple agents within a drug class is a common practice (with a tendency to also group data across ARBs and ACEIs to assess the broader RAAS inhibitor category) and may yield clinically interesting information, the results

Figure 2. Schematic representation of the central role played by angiotensin (Ang) type 1 receptor-mediated signaling in hypertension and cardiovascular disease progression. ${ }^{5} \mathrm{AT}_{1} \mathrm{R}=$ angiotensin type 1 receptor; $\mathrm{BP}=$ blood pressure $\mathrm{MI}=$ myocardial infarction; $\mathrm{NE}=$ norepinephrine.

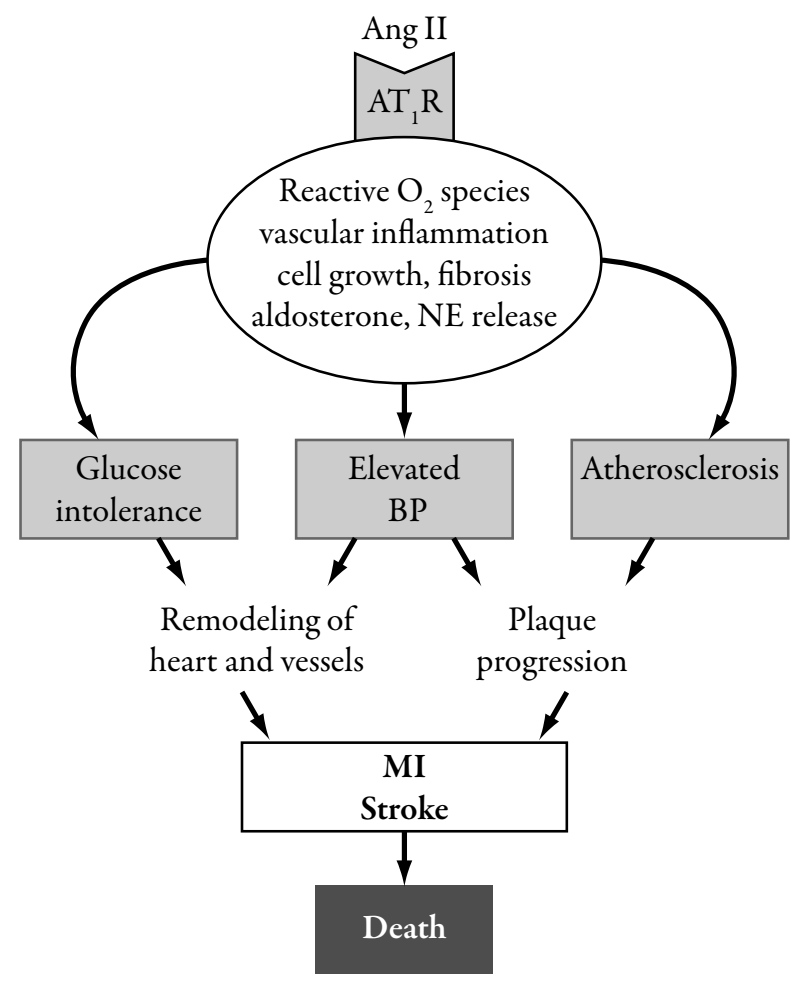

and conclusions should not be interpreted as implying an overall class effect. In the case of the ARBs, important differences exist across the pharmacologic and pharmacokinetic profiles of the individual agents, including their binding affinity and selectivity for the angiotensin II type 1 receptor $\left(\mathrm{AT}_{1}\right) .{ }^{4}$ When given at their highest recommended doses for the treatment of hypertension, differences in BP lowering have been described. ${ }^{23}$ Clinically, the extent to which the $\mathrm{AT}_{1}$ binding affinity/selectivity-related differences within the ARB class influence BP control or long-term cardiorenal morbidity/ mortality is unknown. ${ }^{4}$

The vast randomized controlled trial (RCT) experiences during which ARB-associated effects on outcomes beyond BP control have been compared with those for non-ARB agents are captured in Table 2. ${ }^{24-105}$ Herein, key RCTs of ARBs are reviewed with the intent to identify any notable distinctions among losartan, the first ARB introduced to treatment, and the other ARBs (valsartan, candesartan, irbesartan, telmisartan, eprosartan, or olmesartan) in terms of effectiveness outside of BP control. Relevant RCT data across the various agents will be discussed as well as additional RCTs, irrespective of size, that directly compared losartan against another ARB.

\section{CLINICAL OUTCOMES BEYOND BP LOWERING IN RCT}

\section{Atherosclerosis}

Key RCT Data for Losartan
Data for the antiatherosclerotic effects
of losartan compared with another
antihypertensive agent are only available
from very small series, including a 57-patient
Japanese study in which losartan led to no
change in carotid intima-media thickness (IMT) 


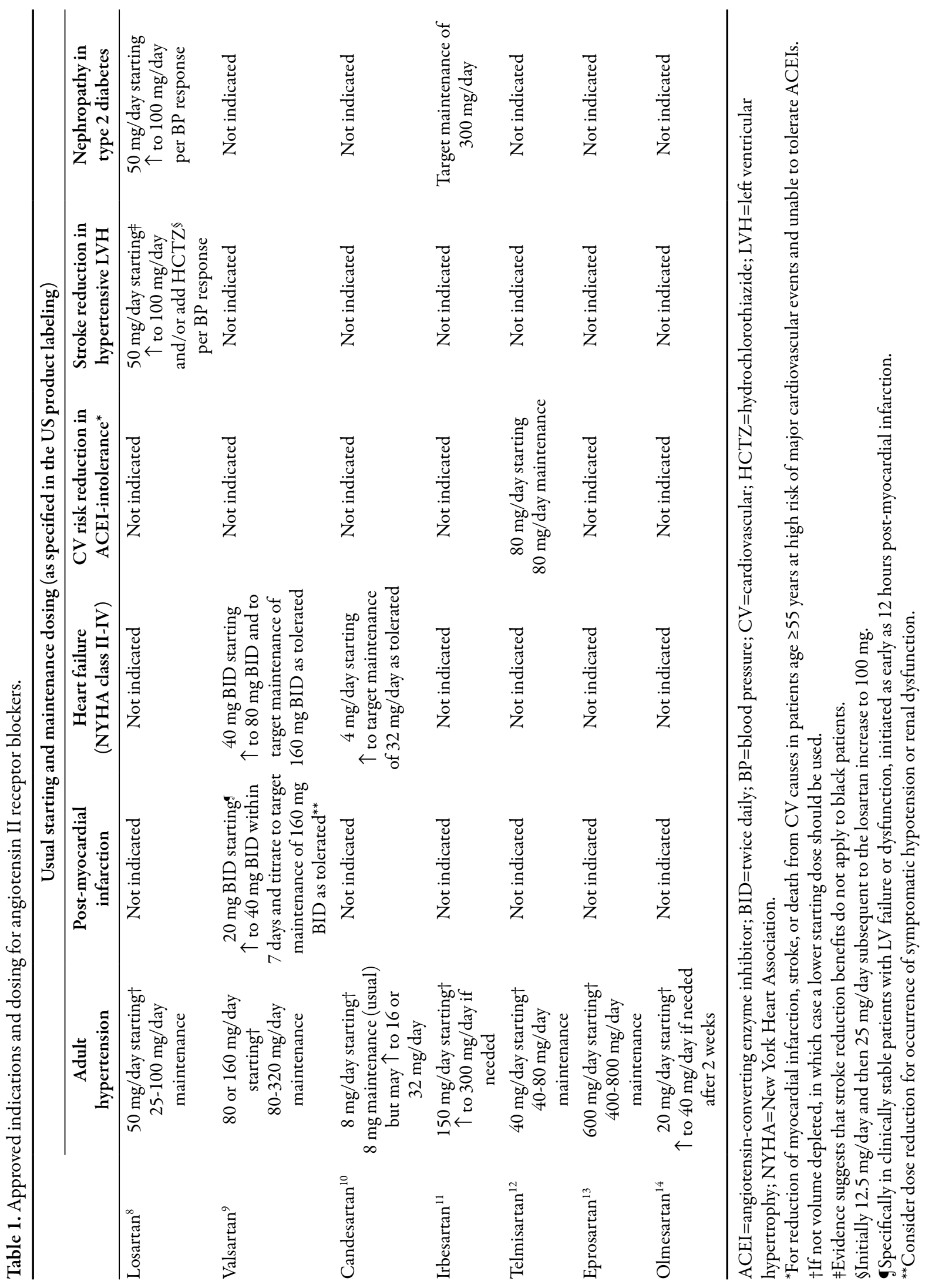




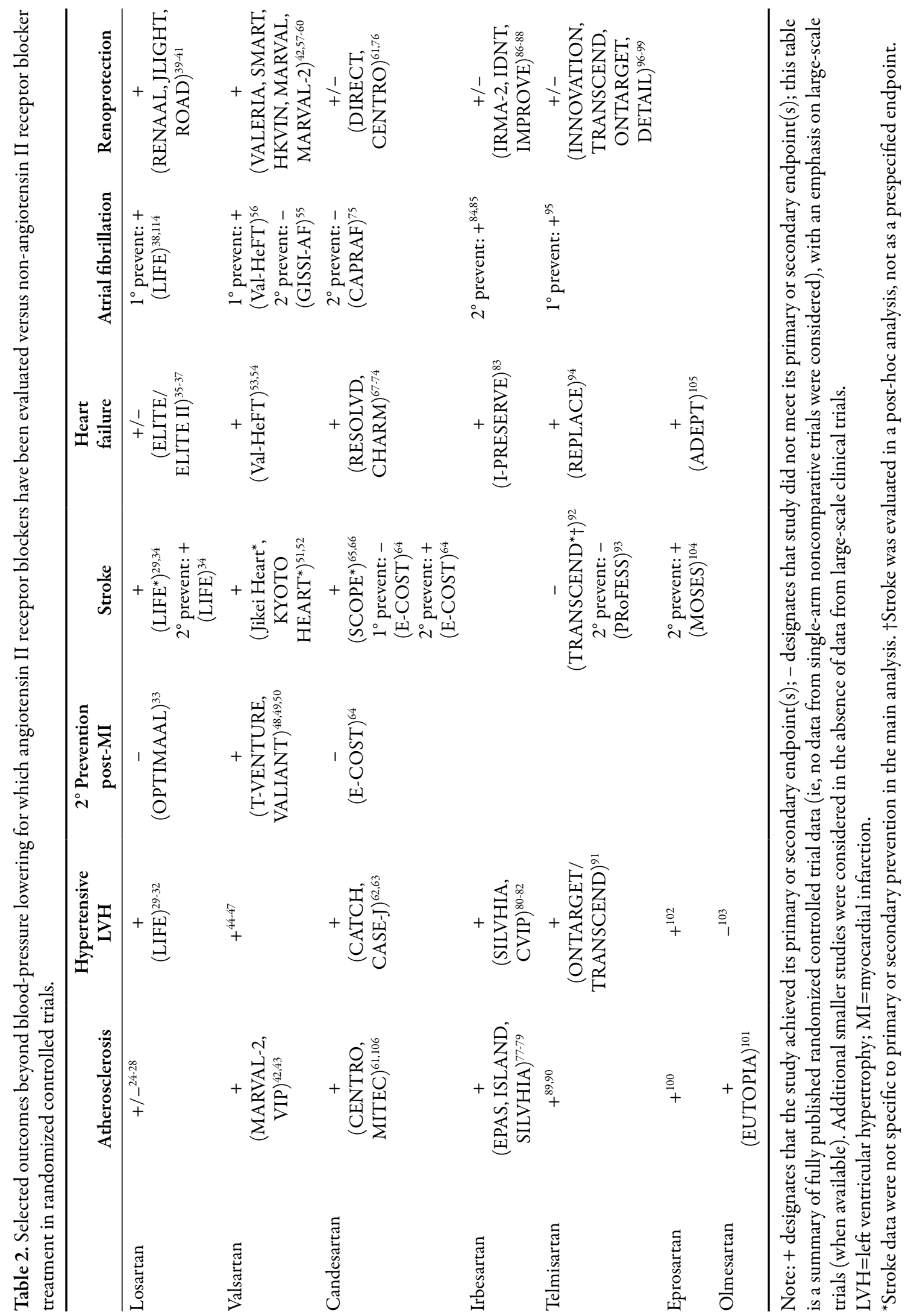


among patients with hypertension (compared with a significant decrease with quinapril), ${ }^{24}$ and a 13-patient Swedish study that showed significant improvement in endothelial function with losartan compared with atenolol in a hypertensive T2D population. ${ }^{25}$ Improvements in arterial stiffness have likewise been reported for losartan in small hypertensive and hemodialysis populations, with effects similar to an ACEI in both settings and effects greater than atenolol for hypertension. ${ }^{26-28}$

\section{Key RCT Data for Other ARBs}

In the AAA study (for definitions of trial name abbreviations see the Appendix at the end of this document), the reduction in IMT was significantly greater in amlodipine recipients than in ARB recipients, with a mean reduction of $-0.046 \mathrm{~mm}$ compared with a mean increase of $0.080 \mathrm{~mm}$ in the ARB group $(P<0.05) .{ }^{106}$ The authors noted that the lack of ARB effect on IMT was an unexpected finding, and that the difference in IMT reduction was not attributable to a difference in BP reduction because there was no significant difference between amlodipine and ARB treatment in that regard. ${ }^{106}$ Other published RCT data pertaining to the potential antiatherosclerotic effects of the individual ARBs, including parameters related to endothelial function and arterial stiffness, are summarized in Table 3. ${ }^{42,61,77,101,107}$ Results of the MITEC study, in which 209 patients with T2D and mild-tomoderate essential hypertension were randomly assigned to receive candesartan 8-16 mg/day or amlodipine $5-10 \mathrm{mg} /$ day (with addition of hydrochlorothiazide as needed), were recently published. ${ }^{107}$ MITEC, specifically designed with the primary objective of determining the relative effects of candesartan and amlodipine on carotid artery IMT, was originally designed as a 3-year study but was closed early because of a high rate of early withdrawals (primarily for lack of BP control). Analysis of the data showed similar reductions from baseline to month 12 , month 24 , and last study visit in both treatment groups, with no statistically significant between-group differences at any time point. An encouraging finding was that more than $50 \%$ of patients per arm $(56.5 \%$ and $59.0 \%$ of candesartan and amlodipine recipients, respectively; $P=0.82$ ) had carotid IMT regression from baseline to last study visit, supporting the theory that both

Table 3. Examples of antiatherosclerotic effects in selected randomized controlled trials* of angiotensin II receptor blockers.

\begin{tabular}{lll}
\hline Agent & Study & Key findings \\
\hline Valsartan & MARVAL-2 & $\begin{array}{l}\text { Significant reduction in arterial stiffness with valsartan/HCTZ vs. amlodipine/HCTZ } \\
\text { in hypertensive patients with albuminuria, which was independent of BP lowering }\end{array}$ \\
Candesartan & CENTRO & $\begin{array}{l}\text { Similar effects vs. enalapril on inflammatory markers of atherosclerosis in hypertensive } \\
\text { patients with T2D }\end{array}$ \\
& MITEC & $\begin{array}{l}\text { Similar effects vs. amlodipine on carotid IMT in hypertensive patients with T2D } \\
\text { Irbesartan }\end{array}$ \\
& SILVHIA & $\begin{array}{l}\text { Greater effectiveness vs. atenolol in reducing common carotid IMT in hypertensive } \\
\text { patients with LVH }\end{array}$ \\
& EUTOPIA & $\begin{array}{l}\text { Greater effectiveness vs. placebo in significantly reducing vascular microinflammation } \\
\text { in a hypertensive population with a high prevalence of atherosclerotic disease }\end{array}$
\end{tabular}

$\mathrm{BP}=$ blood pressure; $\mathrm{HCTZ}=$ hydrochlorothiazide; $\mathrm{IMT}=$ intima-media thickness; $\mathrm{LVH}=$ left ventricular hypertrophy; $\mathrm{T} 2 \mathrm{D}=$ type 2 diabetes.

*In which the overall study population included $>100$ patients. 
agents affect the natural progression of carotid IMT in hypertensive patients with T2D.

\section{Comparative Trials of Losartan Versus Other ARBs}

The AAA study was a Japanese open-label RCT that compared the impact of amlodipine (2.5-5 mg/day) and ARB treatment (losartan, telmisartan, valsartan, or candesartan) on the IMT of the carotid wall in 104 hypertensive patients with T2D. ${ }^{106}$ Although losartan was a treatment option in the AAA study, only one patient received losartan. The results, as reported, provide no insight into the relative effects of the various ARBs because they only describe the ARB group as a whole.

\section{Comment on the Antiatherosclerosis}

\section{Experience With Losartan Versus Other ARBs}

Favorable antiatherosclerotic effects have been documented for losartan and for other ARBs in small RCTs. However, large-scale RCT data are lacking and, therefore, preclude any conclusions supporting or refuting the role of ARBs in improving atherosclerosis-related outcomes. The relative effect of losartan versus the effect of other ARBs on parameters, such as carotid IMT, is unknown.

\section{Left Ventricular Remodeling in Hypertensive Patients}

\section{Key RCT Data for Losartan}

Benefits of losartan with respect to $\mathrm{LVH}$ regression were evident in the results of the primary analysis and a series of subanalyses of the landmark LIFE study. In this study, more than 9000 patients with previously treated or untreated hypertension and electrocardiography (ECG)-documented LVH received losartan $50-100 \mathrm{mg} /$ day or atenolol 50-100 mg/day. Hydrochlorothiazide was added as needed. ${ }^{29}$
Publications derived from the LIFE study collectively support that losartan is significantly more effective than atenolol in not only reducing the composite of CV mortality/stroke/MI (primary endpoint), but also regressing $\mathrm{LVH}$, as defined by the Cornell voltage-duration product and Sokolow-Lyon voltage criteria. ${ }^{29-32}$ After 1 year of treatment, patients with LV mass regression had significantly improved LV diastolic filling, an effect independent of BP lowering. ${ }^{108}$ In another substudy, involving 754 LIFE participants with serial LV mass determinations at baseline and after 12 and 24 months, significant reductions in LV mass and relative wall thickness were seen during the second year of the study (despite only minor BP reductions beyond those achieved during the first year), supporting the theory that the benefits of sustained BP control continue to accrue over at least 2 years of treatment despite a plateau in BP reduction. ${ }^{109}$

\section{Key RCT Data for Other ARBs}

Several other ARBs have been shown to improve hypertensive $\mathrm{LVH}$ relative to atenolol. In the SILVHIA study $(n=115)$, similar $B P$ reductions but significantly greater LV mass reductions were seen with irbesartan 150-300 mg/day compared with atenolol 50-100 mg/day ( \pm hydrochlorothiazide and felodipine as needed). ${ }^{80,81}$ These regimens were also compared in the CVIP study $(n=240)$, which showed significant reductions in $\mathrm{LVH}$ voltage for irbesartan 150-300 mg/day compared with atenolol 50-100 mg/day (with hydrochlorothiazide and amlodipine as needed) after 6 and 18 months of treatment. LV mass reduction was not evident in the overall population but was seen after 18 months in patients with the highest baseline LV mass index values, with a numerically but not significantly greater reduction for irbesartan in this subgroup. ${ }^{82}$ Similarly, in a small RCT $(n=69)$, treatment with 
valsartan $80-160 \mathrm{mg} /$ day ( \pm hydrochlorothiazide) for 8 months reduced LV mass index to a significantly greater extent than did atenolol 50-100 mg/day ( \pm hydrochlorothiazide). ${ }^{46}$

There are other studies of ARB-induced effects on hypertensive LVH in which an agent other than atenolol was selected as the comparator regimen. For example, the effectiveness of candesartan in attenuating LVH in hypertensive populations was shown to be greater than that of amlodipine (in the CASE-J study [ $n=4703])^{63}$ and similar to that of enalapril (in the CATCH study $[n=239]) .{ }^{62}$ Each study supported similar BP-lowering effectiveness when the study regimens were compared. Most recently, LVH-focused results were published together for the ONTARGET $(n=25,620)$ and TRANSCEND $(n=5926)$ studies, both of which were international RCTs that enrolled patients at high risk for $\mathrm{CV}$ disease without $\mathrm{HF}$ or $\mathrm{LV}$ dysfunction and included ECG-determined LVH assessments. ${ }^{91}$ Telmisartan was associated with a significant $24 \%$ reduction in the adjusted odds of LVH $(P=0.0015)$ during the 5-year follow-up of the placebo-controlled TRANSCEND, with a significant $35 \%$ reduction in new-onset $\mathrm{LVH}$ $(P=0.0001)$ and a nonsignificant $9 \%$ odds of LV regression $(P=0.49)$ for those with baseline LVH. Within the latter group, the LV regression subset had a significantly greater systolic BP reduction than the $L V$ persistence subset (6.8 vs. $3.9 \mathrm{mmHg}$; $<<0.0001)$. In ONTARGET, there was an $8 \%$ lower odds of LVH for telmisartan than ramipril that approached but did not reach significance $(P=0.07) .{ }^{91}$ Comparisons of ARBs against amlodipine in small series in hypertension-associated LVH have produced variable findings. Whereas significantly greater LV mass reduction was seen with valsartan compared with amlodipine after 8 months in a Japanese study (along with significant reductions in monocyte-reactive oxygen species and C-reactive protein) ${ }^{47}$ no significant reduction was evident after 1 year of olmesartan or amlodipine in a more recently published US study. ${ }^{103}$

\section{Comparative Trials of Losartan Versus Another ARB}

A small Italian RCT evaluated losartan (50-100 mg/day) and valsartan (80-160 mg/day) on LVH and LV function in 32 patients with mild to moderate untreated essential hypertension and associated concentric LVH, known to confer a particularly high risk for CV disease. ${ }^{110}$ Over 6 months, the regimens reduced systolic and diastolic BP to a similar degree. Significant reductions in LV mass index from baseline to the end of the 6-month study were observed with valsartan and with losartan; the effect for valsartan was significantly greater $(P<0.05$ vs. losartan). Significant improvements in predicted midwall fractional shortening and early peak/peak atrial velocity ratio occurred in both groups (no significant between-group differences), supporting the theory that the LV mass index reductions were associated with improvements in LV midwall systolic performance and in diastolic function in patients with concentric LVH.

\section{Comment on the Hypertensive LVH Experience With Losartan Versus Other ARBs}

The LIFE study of losartan showed favorable effects on hypertensive LVH. Encouraging data have been accumulating across various other ARBs. The results of one RCT of losartan compared with another ARB (valsartan) in hypertensive LVH have been published-a small study that showed a larger effect for valsartan on LV mass. ${ }^{110}$ However, it is insufficient for ascertaining clinically meaningful distinctions between these ARBs. Overall, with BP during treatment consistently noted to be similar 
between groups in most of the comparative studies described here, the collective experience suggests that LVH improvements in ARB-treated patients with hypertension are independent of BP-lowering efficacy.

\section{Secondary Prevention After MI}

\section{Key RCT Data for Losartan}

Based on the OPTIMAAL study, losartan is not a suitable replacement for an ACEI after MI. ${ }^{33}$ In this European study, nearly 5500 patients with confirmed acute MI and HF during the acute phase (or new Q-wave anterior infarction or reinfarction) were randomized to receive losartan (starting and target doses of $12.5 \mathrm{mg}$ /day and $50 \mathrm{mg} /$ day, respectively) or captopril (starting and target doses of $6.25 \mathrm{mg}$ and $50 \mathrm{mg}$ three times daily, respectively), with all-cause mortality as the primary endpoint. At the study end, mean doses being received were losartan $45 \mathrm{mg}$ /day and captopril $44 \mathrm{mg}$ three times daily. Regarding BP assessment, measurements were taken for 6 hours after the first dose and as part of the study follow-up, with significantly greater BP reduction seen during the first 2 hours with the starting dose of captopril $6.25 \mathrm{mg}$ compared with losartan $12.5 \mathrm{mg}$. Specifically, at 1 hour post-first-dose, mean BP was 114/66 $\mathrm{mmHg}$ for captopril versus $119 / 69 \mathrm{mmHg}$ for losartan $(P<0.0001)$. The authors noted that BP was otherwise similar between the two groups. After a 2.7year mean follow-up, the mortality rate was $18 \%$ in the losartan group and $16 \%$ in the captopril group, translating into a $13 \%$ greater risk for death with losartan that approached significance $(P=0.07)$.

\section{Key RCT Data for Other ARBs}

Valsartan has been shown to affect post-MI LV function to the same degree as an ACEI, supporting its approval for this indication. The VALIANT study, a three-arm comparison of valsartan (160 mg twice daily), captopril (50 $\mathrm{mg}$ three times daily), or valsartan $(80 \mathrm{mg}$ twice daily) plus captopril (50 $\mathrm{mg}$ three times daily) in nearly 15,000 patients with MI with complicating HF and/or LV dysfunction, showed no significant difference across the arms with respect to the primary endpoint of CV morbidity/mortality. ARB or ACEI monotherapy, however, was advantageous over combination treatment in terms of adverse events. ${ }^{48}$ Per noninferiority analyses, valsartan was at least as effective as captopril in terms of preventing CV morbidity/mortality. A subset of the VALIANT participants were enrolled into the VALIANT Echo substudy ( $n=610)$, which found that the three study regimens also were similarly effective in improving ventricular structure and function over the 20-month post-MI period. ${ }^{49}$

Recently published results of another RCT of valsartan compared with ACEI post-MI treatment, the T-VENTURE study, are consistent with those of VALIANT. ${ }^{50}$ In this Japanese study that enrolled 256 patients with first acute MI, valsartan (dosed to a target of $160 \mathrm{mg} /$ day) was as effective as an ACEI (one of seven agents) in protecting against LV dysfunction, as determined by left ventriculography repeated at 6 months after MI. ${ }^{50}$ Another Japanese Study known as E-COST evaluated candesartan compared with other non-ARB/ ACEI antihypertensive treatment on CV morbidity/mortality in 2048 patients with essential hypertension, showing a significant $57 \%$ reduction in MI $(P<0.05)$. However, this finding was largely influenced by a $76 \%$ reduction among patients with no history of a CV event, with an insignificant $26 \%$ reduction among patients who experienced a previous MI or stroke. ${ }^{64}$ 
Comment on the Secondary Prevention PostMI Experience With Losartan Versus Other ARBS

Available RCT post-MI data for losartan, from a single trial, do not support benefits in this setting. Valsartan has been shown to be as effective as an ACEI in improving post-MI LV function and, therefore, has regulatory approval for this use. The relative post-MI effects of losartan compared with the other ARBs are unknown.

\section{Stroke}

\section{Key RCT Data for Losartan}

In the LIFE study, stroke was included as part of the primary composite endpoint, along with MI and CV mortality rate. ${ }^{29}$ The ability of losartan to reduce the incidence of stroke by $25 \%$ (5\% vs. $7 \%$ with atenolol; $P=0.001$ ) ranks among the most clinically notable findings of the LIFE study. ${ }^{29}$ Stroke prevention was also evident in a subanalysis of the LIFE trial that focused on a subset of 6886 patients without known vascular disease. ${ }^{111}$ As in the overall population, BP reductions were similar in this subset regardless of treatment with losartan or atenolol. However, with losartan there was a significant $19 \%$ reduction in the composite endpoint of CV death, stroke, and MI ( $P=0.008)$, which included an even greater $34 \%$ reduction in incident stroke $(P<0.001) .{ }^{111}$ Subanalysis by race showed that black individuals treated with losartan were actually at increased risk for stroke events than black individuals who received atenolol (unadjusted hazard ratio, 1.99), and this approached statistical significance $(P=0.051) .^{34}$ Another LIFE subanalysis provided information for specific stroke subtypes, with a significant $35 \%$ reduction for losartan in terms of fatal stroke $(P=0.032)$ and significant $27 \%$ reductions for the ischemic $(P=0.001)$ and atherothrombotic
$(P=0.002)$ subtypes. ${ }^{34}$ Incidences of embolic, hemorrhagic, and other/unclassified stroke were not significantly different between the two groups. The difference in recurrent stroke, however, was significant $(P=0.017)$ with 26 losartan recipients compared with 46 atenolol recipients experiencing two or more incident strokes during the study follow-up.

\section{Key RCT Data for Other ARBs}

As in LIFE, ${ }^{29,34}$ most of the trials that evaluated stroke prevention for the other ARBs (Table 4) included incident stroke within the primary composite endpoint of CV morbidity/ mortality, an exception being the PRoFESS $(n=20,332)$ secondary prevention study of telmisartan. Telmisartan had no impact on the primary endpoint of recurrent stroke after a 2.5year mean follow-up in PRoFESS ${ }^{93}$ or on the composite component of stroke in the placebocontrolled TRANSCEND $(n=5926) .{ }^{92}$

Encouraging stroke prevention data have also been reported for valsartan, ${ }^{51,52}$ eprosartan (specifically as secondary prevention), ${ }^{104}$ and candesartan. ${ }^{64,65}$ For example, in the Jikei Heart Study, valsartan 40-160 mg/day or a non-ARB was added to conventional treatment in 3081 Japanese patients with hypertension, coronary heart disease, and/or heart failure. ${ }^{51}$ The addition of valsartan lowered the incidence of stroke or transient ischemic attack by $40 \%$, compared with non-ARB treatment $(P=0.028)$. Similarly, in the KYOTO HEART Study $(n=3031)$, the addition of valsartan 40-160 $\mathrm{mg} /$ day to existing treatment in Japanese patients with high-risk hypertension reduced the incidence of stroke or transient ischemic attack by $45 \%$, compared with nonARB treatment $(P=0.015) .{ }^{52}$ In the placebocontrolled SCOPE trial, in nearly 5000 patients 70-89 years of age with mild to moderate hypertension, candesartan 8-16 mg/day was 
Table 4. Examples of stroke-preventative effects in selected randomized controlled trials* of angiotensin II receptor blockers.

\begin{tabular}{|c|c|c|}
\hline Agent & Study & Key findings \\
\hline Losartan & LIFE & $\begin{array}{l}\text { Overall stroke: significant stroke reduction vs. atenolol }(25 \% ; P=0.0010),{ }^{29} \text { with } \\
\text { significant reductions in a subset without clinical vascular disease }(34 \% ; P<0.001)^{111} \\
\text { and in ischemic }(27 \% ; P=0.001) \text {, atherothrombotic }(27 \% ; P=0.002) \text {, and fatal } \\
(35 \% ; P=0.032) \text { stroke in a subanalysis of specific subtypes }{ }^{34} \\
\text { Secondary prevention: significant reduction }(n=26 \text { vs. } n=46 ; P=0.017) \text { in subtype- } \\
\text { focused analysis }^{34}\end{array}$ \\
\hline \multirow[t]{2}{*}{ Valsartan } & Jikei Heart Study & $\begin{array}{l}\text { Overall stroke: significant reduction vs. non-ARB regimens }(40 \% ; P=0.028) \text { in stroke } \\
\text { or transient ischemic attack in patients with hypertension, coronary heart disease, and/ } \\
\text { or heart failure }\end{array}$ \\
\hline & $\begin{array}{l}\text { KYOTO HEART } \\
\text { Study }\end{array}$ & $\begin{array}{l}\text { Overall stroke: significant reduction vs. non-ARB regimens }(45 \% ; P=0.015) \text { in } \\
\text { stroke or transient ischemic attack in patients with hypertension at high risk for } \\
\text { cardiovascular events }\end{array}$ \\
\hline \multirow[t]{2}{*}{ Candesartan } & SCOPE & $\begin{array}{l}\text { Overall stroke: significant reduction vs. placebo }(28 \% ; P=0.04) \text { in nonfatal stroke in } \\
\text { elderly hypertensive patients, }{ }^{65} \text { with significant all-stroke reduction in a subset with } \\
\text { isolated systolic hypertension }{ }^{66}\end{array}$ \\
\hline & E-COST & $\begin{array}{l}\text { Primary prevention: no significant stroke reduction vs. conventional antihypertensive } \\
\text { treatment, with a } 29 \% \text { increased risk with candesartan in patients without history of } \\
\text { stroke or } \mathrm{MI}^{64} \\
\text { Secondary prevention: significant stroke reduction for candesartan vs. conventional } \\
\text { antihypertensive treatment in patients with past stroke or } \mathrm{MI}(61 \% ; P<0.01)^{64}\end{array}$ \\
\hline \multirow[t]{2}{*}{ Telmisartan } & PRoFESS & $\begin{array}{l}\text { Secondary prevention: no significant recurrent stroke reduction (primary endpoint) } \\
\text { vs. placebo when initiated within } 90 \text { days after ischemic stroke }{ }^{93}\end{array}$ \\
\hline & TRANSCEND & $\begin{array}{l}\text { Overall stroke: no significant stroke reduction vs. placebo in ACEI-intolerant patients } \\
\text { with cardiovascular disease or diabetes/end-organ damage }\end{array}$ \\
\hline Eprosartan & MOSES & $\begin{array}{l}\text { Secondary prevention: significant reduction vs. nitrendipine }(25 \% ; P=0.026) \text { in fatal/ } \\
\text { nonfatal cerebrovascular events }{ }^{104}\end{array}$ \\
\hline
\end{tabular}

$\mathrm{ACEI}=$ angiotensin-converting enzyme inhibitor; $\mathrm{ARB}=$ angiotensin $\mathrm{II}$ receptor blockers; $\mathrm{MI}=$ myocardial infarction.

${ }^{*}$ In which the overall study population included $>100$ patients.

associated with a significant $28 \%$ reduction in nonfatal stroke $(P=0.04)$ and a $24 \%$ allstroke reduction of borderline significance $(P=0.056) .{ }^{65}$ In a subanalysis of patients with isolated systolic hypertension, there was a significant $42 \%$ reduction in fatal/nonfatal stroke $(P=0.05) .{ }^{66}$ In the aforementioned E-COST evaluation of candesartan compared with other non-ARB/ACEI antihypertensive treatment in 2048 patients with essential hypertension, there was a significant 39\% reduction $(5.8 \%$ vs. $9.4 \% ; P<0.05)$ in stroke incidence for candesartan overall that was driven by the $61 \%$ reduction ( $18.3 \%$ vs. $46.9 \%$; $P<0.01)$ in patients with a CV history of stroke or MI. ${ }^{64}$ From a primary prevention standpoint, however, the incidence of stroke was increased among those who received candesartan instead of the conventional treatment $(3.5 \%$ vs. $1.2 \%$; $P$ value not reported). 


\section{Comment on Stroke Prevention Experience With Losartan Versus Other ARBs}

Losartan lowered the risk for first stroke in the LIFE study, an effect that has since been documented for valsartan (in Jikei Heart and KYOTO HEART) and candesartan (in SCOPE but not in E-COST). In terms of secondary prevention, losartan appears to be effective (also per LIFE); however, the experiences with the other ARBs have been mixed. For losartan, stroke reduction in hypertensive patients with $\mathrm{LVH}$ is an approved indication. The relative effectiveness of losartan compared with other ARBs for primary or secondary stroke prevention is unknown.

\section{Heart Failure}

\section{Key RCT Data for Losartan}

The ELITE trial, a 48-week study in 722 elderly, ACEI-naive patients with symptomatic HF, demonstrated a $9.4 \%$ rate of death and/or HF-related hospitalization for losartan (50 mg/day) compared with $13.2 \%$ for captopril (50 mg three times daily). ${ }^{35}$ Although this $32 \%$ risk reduction was not significant $(P=0.075)$, there was a significant difference in the all-cause mortality rate: $4.8 \%$ for losartan compared with $8.7 \%$ for captopril, a $46 \%$ reduced risk of death $(P=0.035)$ that appeared to be largely influenced by a reduction in the occurrence of sudden cardiac death $(1.4 \%$ vs. $3.8 \%)$. In the ELITE ventricular function substudy, in which 29 patients underwent radionuclide ventriculography at baseline and after 48 weeks, losartan and captopril; prevented LV dilation to a similar degree, whereas only captopril induced reverse remodeling. ${ }^{36}$ The intriguing survival benefit of losartan in ELITE prompted the design of a larger RCT of losartan compared with captopril to further assess mortality rate in a similar HF population (ELITE II $[n=3152])$. Unlike in
ELITE, however, the advantages for losartan in ELITE II pertained only to adverse event-related discontinuation rates, thereby suggesting that the between-group mortality rate differences in ELITE were likely the product of chance. ${ }^{37}$ No differences between the two groups were apparent in the main ELITE II efficacy results (ie, all-cause mortality [primary endpoint], sudden death or resuscitated arrest, or all-cause mortality or hospitalization) $)^{37}$ or in a subsequent report focused on HF-related outcomes (mortality, hospitalizations, discontinuations, change in New York Heart Association [NYHA] class, and quality of life [with significant improvements in the latter two parameters in both groups]). ${ }^{112}$

\section{Key RCT Data for Other ARBs}

Candesartan has shown favorable effects on ventricular function in patients with $\mathrm{HF}$, initially in the RESOLVD study $(n=768)$ in which the combination of candesartan and enalapril showed promise in preventing LV remodeling among patients with NYHA class II-IV congestive $\mathrm{HF}$ (CHF). ${ }^{67}$

The CHARM program consisted of three concurrently conducted placebo-controlled RCTs in the following three symptomatic HF populations, based on LV ejection fraction (LVEF) and concurrent treatment: (1) patients with LVEF $>40 \%$ (CHARM-Preserved); (2) LVEF $\leq 40 \%$ receiving an ACEI (CHARM-Added); (3) and LVEF $\leq 40 \%$ not receiving an ACEI owing to intolerance (CHARM-Alternative). A series of reports based on the overall CHARM program $(n=7599)$, for which the primary outcome was all-cause mortality (23\% candesartan vs. $25 \%$ placebo; $P=0.055$ [unadjusted] or $P=0.032$ [covariate adjusted]), support significant benefits for candesartan $32 \mathrm{mg}$ /day in improving the rates of $\mathrm{CV}$ death and HF-related hospitalization, ${ }^{68}$ sudden death and death from worsening HF, ${ }^{69}$ and NYHA functional class. ${ }^{70}$ In a combined 
analysis of CHARM-Added and CHARMAlternative, all-cause mortality, CV death, and HF hospitalizations were significantly lower for candesartan than for placebo in HF patients with LVEF $\leq 40 \% .{ }^{71}$ Improvements in the primary outcome established for the individual trials (ie, CV death or unplanned hospitalization for management of worsening $\mathrm{CHF}$ ) were achieved in CHARM-Added, including the subset of patients also receiving a beta-blocker, ${ }^{72}$ and CHARMAlternative $^{73}$ but not in CHARM-Preserved. ${ }^{74}$ (However, this third trial in patients with LVEF $>40 \%$ showed fewer HF-related hospitalizations among candesartan recipients.)

The Val-HeFT study ( $n=5010)$ was designed to determine whether reductions in morbidity/ mortality rate could be achieved by adding valsartan (target dose $160 \mathrm{mg}$ twice daily) compared with placebo to an existing HF drug regimen (93\% of patients were on ACEIs, $86 \%$ diuretics, $67 \%$ digoxin, and $35 \%$ beta-blockers), using coprimary endpoints of mortality alone or with morbidity (ie, cardiac arrest with resuscitation, HF-related hospitalization, or outpatient administration of intravenous inotropic or vasodilator drugs for $\geq 4$ hours). ${ }^{53}$ Mortality rate was nearly identical in the valsartan and placebo groups, at $19.7 \%$ and $19.4 \%$, respectively. However, the combined mortality/morbidity outcome improved significantly among valsartan recipients to $28.8 \%$ compared with $32.1 \%$ with placebo, a significant $13 \%$ risk reduction $(P=0.009)$. Within the mortality/morbidity composite, there was a notable difference in the rate of HF-related hospitalization: $13.8 \%$ compared with $18.2 \%$ with placebo. In the subset of patients who were not treated with an ACEI ( $n=366)$, regardless of beta-blocker use, valsartan treatment reduced the risk of morbidity/mortality by $44 \%$ and the risk of mortality by $33 \%$ compared with placebo. ${ }^{53}$ However, in the subgroup receiving valsartan, an ACEI, and a beta-blocker, mortality was significantly increased by approximately $40 \%(P=0.009)$ and there was a trend toward higher morbidity/mortality (nonsignificant $20 \%$ approximate increase; $P=0.10$ ). This finding suggested a potential negative effect of blocking multiple neurohormonal systems in patients with HF.

The reason for the difference between CHARM-Added and Val-HeFT with respect to the subset receiving triple therapy with an ARB, ACEI, and beta-blocker is not altogether clear. There are several differences between CHARM and Val-HeFT that could have influenced the results and may explain the differences between their outcomes. Compared to CHARM, Val-HeFT involved mainly NYHA class II patients and utilization of digoxin was higher while betablocker use was much lower (35\%). CHARM involved more patients with NYHA class III disease, diabetes, and ischemic heart disease, and more patients receiving beta-blockers, spironolactone, and diuretics. The Val-HeFT echocardiographic study, which focused on measurements of LV internal diastolic diameter and LVEF, showed significant improvements in both parameters when valsartan was coadministered with an ACEI (without betablocker) or beta-blocker (without ACEI), but not when added to ACEI/beta-blocker combination treatment. ${ }^{54}$ In patients who did not receive either an ACEI or a beta-blocker, treatment with valsartan significantly improved LV internal diastolic diameter and nonsignificantly improved LVEF. An additional analysis of the Val-HeFT echocardiographic data determined that the patients with the most severe LV remodeling derived the greatest benefit from valsartan. ${ }^{113}$

More recently, the placebo-controlled I-PRESERVE study $(n=4128)$ failed to show improved outcomes for irbesartan $300 \mathrm{mg}$ /day in patients with NYHA class II-IV HF with an 
LVEF $\geq 45 \% .{ }^{83}$ Although RCT data are also available for eprosartan and telmisartan, they represent smaller, shorter-term studies that do not provide insight into the long-term benefits of these ARBs in patients with HF. ${ }^{94,105}$

\section{Comment on the HF Experience With Losartan Versus Other ARBs}

Although ELITE suggested a role for losartan in patients with HF, no benefit was seen in the confirmatory ELITE II study, and results do not favor the use of losartan as a substitute to an ACEI. Recent data show that, in ACEI-intolerant patients, increased-dose losartan has a greater effect on reducing HF-related hospitalization than the conventional antihypertensive dose. The positive findings of RCTs of valsartan (ValHeFT) and candesartan (CHARM) prompted their approval for use in patients with HF. The extent to which losartan reduces HF-related morbidity/mortality rates relative to the other ARBs is unknown.

\section{Atrial Fibrillation}

\section{Key RCT Data for Losartan}

Data from the LIFE study support that in patients with hypertension and ECG LVH, losartan offers additional advantages over atenolol in the primary prevention of $\mathrm{AF}{ }^{38}$ Among losartan recipients, there was a $33 \%$ lower incidence of new-onset AF, a significant effect $(P<0.001)$ that was independent of other known risk factors incorporated into the multivariate analysis. ${ }^{38} \mathrm{~A}$ subsequent subanalysis found that the effects of losartan in reducing new-onset AF were associated with a reduction in $\mathrm{LVH}$ and independent of $\mathrm{BP}$ lowering. ${ }^{114}$ To better characterize the effects of RAAS blockade in the secondary prevention of $\mathrm{AF}$, without the confounding influence of other comorbidities, Yin et al. randomly assigned
177 patients with lone paroxysmal AF to receive amiodarone alone, amiodarone plus losartan 50-100 mg/day, or amiodarone plus the ACEI perindopril 2-4 mg/day. ${ }^{115}$ In these groups, the incidences of recurrent $\mathrm{AF}$ within 24 months after randomization were $41 \%, 19 \%$, and $24 \%$, respectively, with significant advantages for both combinations compared with amiodarone in Kaplan-Meier analysis ( $P=0.006$ for losartan/ amiodarone; $P=0.04$ for perindopril/amiodarone) and a Cox proportional hazards model (in which the relative risks were $0.36[P=0.006]$ and $0.39[P=0.008]$, respectively). Significant reductions in left atrial diameter were also seen with both combinations relative to amiodarone monotherapy $(P<0.001)$.

\section{Key RCT Data for Other ARBs}

AF-preventing effects have been reported for several other ARBs. In an RCT in 154 patients with a history of persistent AF assessed for recurrence during the 2 months after electrical cardioversion, irbesartan 150-300 mg/day plus amiodarone was associated with an $85 \%$ 2 -month probability of maintaining sinus rhythm compared with $63 \%$ with amiodarone alone. ${ }^{85}$ ARB use was identified as the only significant factor for maintaining sinus rhythm on multivariate analysis, translating into a $65 \%$ lower risk for recurrent $\mathrm{AF}$ than amiodarone alone $(P=0.018)$ and an $81 \%$ reduction in a Cox proportional model that adjusted for factors such as diabetes, bundle-branch block, and AF duration $(P=0.031)$. At last follow-up, after a median of 254 days, the probabilities of maintaining sinus rhythm were $80 \%$ and $56 \%$ for irbesartan/amiodarone and amiodarone, respectively. Valsartan subsequently was found to affect AF based on a post-hoc subanalysis of Val-HeFT that evaluated incident AF after add-on treatment with valsartan (target dose $160 \mathrm{mg}$ twice daily) or placebo in patients 
with class II-IV HF. ${ }^{56}$ In 4395 patients with sinus rhythm at baseline, AF was reported as an adverse event in $5.1 \%$ of valsartan recipients compared with $8.0 \%$ of placebo recipients, translating into a highly significant $37 \%$ relative risk reduction on multivariate analysis $(P=0.0003)$. The placebo-controlled GISSI-AF trial $(n=1422)$ was subsequently designed specifically to evaluate the effects of add-on valsartan (target dose $320 \mathrm{mg} /$ day) on the rate of recurrent $\mathrm{AF}^{55}$ Recently published results revealed no effect for valsartan on the primary outcome of first AF recurrence at 1 year (51\% vs. 52\% for placebo; adjusted hazard ratio $0.97 ; P=0.73$ ) or the rate of multiple $\mathrm{AF}$ recurrences ( $27 \%$ vs. $28 \%$ for placebo; adjusted odds ratio $0.89 ; P=0.34$ ). The results of GISSI-AF were consistent with those previously reported for the smaller CAPRAF study ( $n=171)$, in which postconversion candesartan $16 \mathrm{mg} /$ day was no more effective than placebo in reducing the 6-month rate of recurrent AF among patients not receiving antiarrhythmic treatment. ${ }^{75}$

\section{Comment on the AF Prevention Experience With Losartan Versus Other ARBs}

Data for losartan as AF prevention are limited, yet more favorable overall than those for the other ARBs, considering that negative results have been reported for several ARBs when evaluated specifically in patients with AF. Combining losartan or irbesartan with amiodarone appears to warrant further study in the prevention of recurrent AF. The relative effects of losartan compared with other ARBs as primary or secondary AF prevention are unknown.

\section{Renoprotection}

Data from RCTs detailing the renoprotective effects of ARBs are summarized in Table 5. ${ }^{39-42,57-}$ 61,76,86-88,96-99,116,117

\section{Key RCT Data for Losartan}

Preventing nephropathy in patients with T2D is one of the approved indications for losartan. The results of the RENAAL study, published in 2001, clearly showed renoprotective benefits for losartan in patients with T2D and nephropathy (Table 5). ${ }^{39}$ In RENAAL, 1513 patients received losartan $50-100 \mathrm{mg} /$ day or placebo, in conjunction with conventional antihypertensive treatment, and were followed up for a mean of 3.4 years. The losartan group had a $16 \%$ risk reduction $(P=0.02)$ for the primary composite endpoint of doubling of baseline serum creatinine (SCr), end-stage renal disease (ESRD), or death. The risk reductions for the individual renal outcomes within the composite were also significant (25\% for SCr doubling $[P=0.006]$ and $28 \%$ for ESRD $[P=0.002])$, whereas mortality rate was similar regardless of whether patients received losartan or placebo. The authors noted that differences in trough BP (albeit slightly lower among the losartan recipients) did not explain the renoprotective effects that were observed in RENAAL, with minimal change in the primary composite endpoint after adjusting for BP. ${ }^{39} \mathrm{~A}$ number of smaller studies collectively suggest that the renoprotective effects of losartan treatment extend to populations beyond T2D nephropathy and are not attributable to the antihypertensive effects of losartan (Table 5). ${ }^{40,41}$

The ROAD study $(n=360)$ of ARB or ACEI monotherapy was unique in that it evaluated doses of losartan and benazepril in patients with nondiabetic proteinuria and chronic renal insufficiency titrated based on urinary protein excretion, SCr, and potassium levels, with a median of $100 \mathrm{mg} /$ day for losartan (range $50-200 \mathrm{mg} /$ day) and $20 \mathrm{mg} /$ day for benazepril (range 10-40 mg/day). ${ }^{41}$ By tailoring treatment according to optimal antiproteinuric 


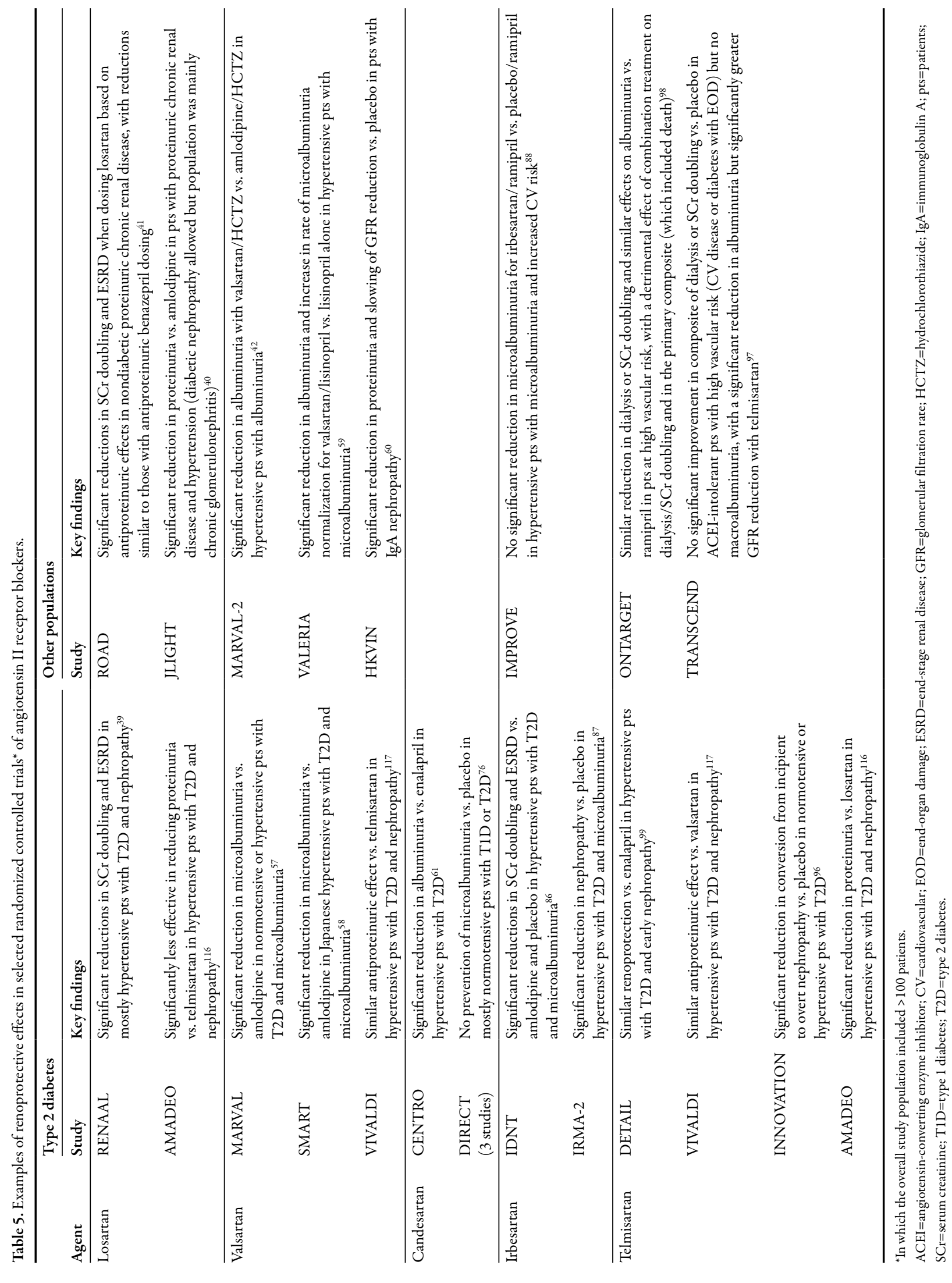


effectiveness, losartan and benazepril significantly reduced the occurrence of SCr doubling, ESRD, or death by $53 \%(P=0.022)$ and $51 \%(P=0.028)$, respectively. There were no efficacy-related differences between losartan and benazepril at the conventional or antiproteinuric doses, and no dose-related increases in BP reduction or in adverse events.

\section{Key RCT Data for Other ARBs}

Much data support the theory that irbesartan (the only ARB other than losartan approved for preventing nephropathy in T2D) and several other ARBs (ie, valsartan, candesartan, and telmisartan) are renoprotective in patients with T2D (Table 5), 57,58,61,86,87,96,99,116,117 more so than amlodipine and similar to ACEIs based on active-controlled evaluations. ${ }^{57,58,86,99} \mathrm{At}$ the recommended target dose of $300 \mathrm{mg} /$ day, irbesartan reduced the risk for SCr doubling/ ESRD/death by $20 \%$ compared with placebo $(P=0.02)$ and $23 \%$ compared with amlodipine $(P=0.006)$ in the IDNT study $(n=1715)^{86,87}$ and the onset of diabetic nephropathy by $70 \%$ compared with placebo $(P<0.001)$ in the IRMA-2 study $(n=590) .{ }^{87}$ The IDNT and IRMA-2 studies both were conducted in hypertensive patients with $\mathrm{T} 2 \mathrm{D}$ and determined that the renoprotection afforded by irbesartan was independent of BP lowering. ${ }^{86,87}$

Reported RCT comparisons involving the other ARBs have shown renoprotective effects in T2D populations (Table 5). In the MARVAL study $(n=332)$, for example, mean urinary albumin excretion rate improved by $44 \%$ at 24 weeks in patients treated with valsartan 80-160 mg/day, compared with only $8 \%$ in patients who received amlodipine $5-10 \mathrm{mg} /$ day $(P<0.001) .{ }^{57} \mathrm{An}$ exception to the favorable results obtained with most ARBs was reported in a pooled analysis of the three placebo-controlled studies within the DIRECT program. ${ }^{76}$ Although the overarching objective of the DIRECT program was to evaluate the effect of candesartan $32 \mathrm{mg} /$ day on retinopathy in patients with diabetes (type 1 or 2), microalbuminuria was designated as a primary endpoint for the pooled analysis. After a 4.7-year median follow-up in the pooled analysis $(n=5231)$, there was a nonsignificant $5 \%$ reduction $(P=0.60)$ in incident microalbuminuria among candesartan recipients compared with placebo recipients. The authors proposed that the lack of renoprotection may have been influenced in part by the dominance of normotensive patients (with a corresponding low vascular risk) in this series of studies. ${ }^{76}$ In this regard, although the majority of data support that ARB-induced renoprotection is not a BP-related phenomenon, there are reports in which improved renal outcomes have been associated with improved BP control. ${ }^{117}$

Overall, RCTs of valsartan, irbesartan, and telmisartan in nondiabetic renal disease have yielded mixed findings. The 133-patient VALERIA study found that the combination of valsartan $320 \mathrm{mg} /$ day plus lisinopril $20 \mathrm{mg} /$ day led to significant improvements in albuminuria and the rate of microalbuminuria resolution over those seen with single-agent valsartan $320 \mathrm{mg} /$ day or lisinopril $40 \mathrm{mg} /$ day. ${ }^{59}$ On the contrary, in the aforementioned ONTARGET study in more than 25,000 patients with atherosclerotic vascular disease or diabetes-related end-organ damage, there was an unexpected worsening in the primary composite outcome (dialysis/ SCr doubling/death) with the combination of telmisartan $80 \mathrm{mg} /$ day plus ramipril $10 \mathrm{mg}$ /day compared with either agent alone (hazard ratio $1.09 ; P=0.037) .{ }^{98}$ The placebo-controlled IMPROVE $(n=405)$ and telmisartan TRANSCEND studies did not show renal benefits for ARB treatment in patients without microalbuminuria at high risk for CV disease. ${ }^{88,97}$ 


\section{Comparative Trials of Losartan Versus Another ARB}

Recognizing that differences in $\mathrm{AT}_{1}$ antagonism across the ARBs may confer renoprotective differences, a small Japanese RCT evaluated the relative merits of perindopril, trandolapril, candesartan, and losartan in 62 hypertensive patients with chronic renal disease, focusing on proteinuria and urinary nitrite/nitrate (NOx) excretion over 96 weeks. ${ }^{118}$ The four agents were similar in their BP reductions and lack of effect on creatinine clearance. When comparing the ARBs, candesartan was more effective than losartan in reducing proteinuria and was associated with sustained antiproteinuric activity during the study (which was not the case for losartan), with a significant difference between candesartan and losartan at study end. Substantial increases in urinary NOx excretion were likewise seen with all agents, except losartan. Overall, these results suggested that the antiproteinuric effects of losartan are less pronounced than those achieved with an ACEI or candesartan.

Losartan is the only ARB with established uricosuric activity. ${ }^{119}$ Accordingly, the results of a South African RCT of the effects of losartan compared with candesartan on uric acid, renal function, and fibrinogen in 59 patients with hypertension and diuretic-associated hyperuricemia pointed to advantages in the losartan arm. ${ }^{119}$ Although BP reductions were similar in the two groups, the losartan group experienced a significant reduction in uric acid levels after 24 weeks and significantly fewer patients had a SCr increase of $10 \%$, compared with the candesartan group $(14.2 \%$ vs. $44 \% ; P<0.02)$.

Hypothesizing that an ARB with high lipophilicity and long half-life (telmisartan) would be more effective in reducing proteinuria than a low lipophilicity ARB with a shorter halflife (losartan), the AMADEO study ( $n=860)$ was conducted using the 52-week difference in the urinary protein/creatinine ratio as the primary endpoint. ${ }^{116}$ This variable decreased significantly $(P<0.0001)$ from baseline to week 52 in both groups; however, the reduction was significantly more pronounced with telmisartan than with losartan (29.8\% vs. $21.4 \% ; P=0.03)$, as were the reductions in several secondary outcomes, including CV morbidity/mortality (21 events vs. 37 events; $P=0.037$ ) and all-cause mortality (two events vs. 13 events; $P=0.007$ ). A $4.2 \mathrm{mmHg}$ difference in systolic BP was seen at week 8 , favoring the telmisartan group; however, differences were much less pronounced at all subsequent time points.

\section{Comment on the Renoprotection Experience With Losartan Versus Other ARBs}

Losartan and irbesartan have an established renoprotective role in patients with $\mathrm{T} 2 \mathrm{D}$ nephropathy. Experiences with these and other ARBs have been consistent in diabetic renal disease but not in nondiabetic renal disease. Some limited evidence from RCTs suggests greater antiproteinuric effects for candesartan (in chronic renal disease) and telmisartan (in T2D nephropathy) than with losartan, which has uricosuric effects that may benefit patients with hyperuricemiaassociated renal disease. The relative impact of losartan compared with other ARBs as renoprotection in diabetic and nondiabetic renal disease is unknown.

Although not the focus of this article, numerous RCTs also support the positive effects of RAAS blockade on the prevention of diabetes (eg, LIFE, SCOPE). Elliott and Meyer conducted a meta-analysis that included 22 RCTs and more than 143,000 patients, most of whom had hypertension. ${ }^{120}$ The antihypertensive class least associated with incident diabetes was the ARBs, with an odds 
ratio of incident diabetes of 0.57 , compared with diuretics $(P<0.0001)$. Further assessment of the role of ARBs in preventing diabetes was addressed in the NAVIGATOR study. This is a large multicenter randomized study with the goal of evaluating the effects of valsartan or nateglinide treatment, individually or combined, on reducing the risk for T2D or $\mathrm{CV}$ events in patients with impaired glucose tolerance. ${ }^{121}$ Recently published results support a modest but statistically significant $14 \%$ reduction in incident T2D with a 5-year course of valsartan versus placebo (33.1\% vs. $36.8 \% ; P<0.001)$ but no $\mathrm{CV}$ event reduction ( $14.5 \%$ vs. $14.8 \% ; P=0.43)$, with improvement in neither outcome with nateglinide versus placebo. ${ }^{122,123}$

\section{CLINICAL PRACTICE CONSIDERATIONS}

The clinical practice considerations taken from the trials discussed for callout are as follows:

- Efficacy and safety results of any given trial of one particular ARB may not be easily extrapolated to another ARB.

- Switching from one ARB to another solely on the basis of cost, irrespective of the clinical trial data available for the specific agents, can have adverse economic implications.

- $\quad$ For effects beyond BP, there is no accepted method for determining which dose of an unstudied ARB might provide similar effectiveness compared with an ARB that has been proven effective in an RCT (ie, there is no dose-equivalency map).

- When treating patients, clinicians should design a treatment plan that takes into consideration all comorbidities/risk factors and choose the ARB that is proven effective, based on RCTs, in their management.
Losartan was the first commercially available $\mathrm{ARB}$ and therefore the first to be available on a generic basis. Although in today's environment of increasing healthcare costs, economic factors play a major role in determining the type of antihypertensive agent prescribed, it is important to also consider clinical evidence from large-scale RCTs in the selection process. Regarding the ARB class of agents, efficacy and safety results of any given trial of one particular agent may not be easily extrapolated to another ARB. Switching from one ARB to another solely on the basis of cost, irrespective of the clinical trial data available for the specific agents, can have adverse economic implications. ${ }^{124}$ For example, in an economic analysis of patients in whom a switch from valsartan to another ARB was prompted by a copayment increase, this nonmedical reason for switching increased the ARB discontinuation rate, hypertension-related outpatient visits, and the number of days of hypertension-related hospitalization, thereby increasing healthcare resource use and costs. ${ }^{124}$ Although RCTs showed differences between ARBs in regard to slowing down the progression in organ damage, data concerning prevention of CV morbidity/mortality are lacking.

Another complicating issue is that, for effects beyond $\mathrm{BP}$, there is no accepted method for determining which dose of an unstudied ARB might provide similar effectiveness compared with an ARB that has been proven effective in an RCT (ie, there is no dose-equivalency map). Although BP control is clearly an important goal of ARB treatment, dosing decisions become more complex when other comorbidities are factored into the equation. In some situations the correlation between BP control and organ protective effects is low, such as in patients with HF (eg, patients with normal BP in Val-HeFT derived benefit from valsartan treatment) or normotensive patients with diabetic nephropathy 
(eg, the IRMA-2 study showed benefit from increasing the irbesartan dose, leading to a significant reduction in albuminuria despite small BP differences). Based on the recent results of the HEAAL study ( $n=3846$ ) (not discussed previously herein because of the lack of a non-losartan arm, and the current maximum dose approved for losartan is $100 \mathrm{mg} /$ day), increasing losartan dosing from $50 \mathrm{mg} /$ day to $150 \mathrm{mg} /$ day in ACEIintolerant patients with HF led to a significant $10 \%$ improvement in reduction in the primary endpoint of death or HF-related hospitalization (43\% vs. $46 \%$; $P=0.027$ ). ${ }^{125}$ However, the results were influenced by a significant reduction for the hospitalization component (13\% reduction: $6.0 \%$ vs. $7.0 \%$ per 100 patient-years; $P=0.025$ ) but not for all-cause mortality (6\% reduction: $7.6 \%$ vs. $8.2 \%$ per 100 patient-years; $P=0.24$ ), illustrating the complexity of correlating dose and long-term outcomes with ARB treatment. From a safety standpoint, the higher losartan dose resulted in significantly higher incidences of renal impairment $(7.1 \%$ vs. $4.7 \% ; P<0.0001)$, hypotension $(2.9 \%$ vs. $2.1 \% ; P=0.002)$, hyperkalemia $(2.8 \%$ vs. $1.9 \% ; P=0.0004)$, and angioedema $(0.08 \%$ vs. $0 \% ; P=0.03)$ but not in significantly higher treatment discontinuation rates attributable to these specific events. Accumulating data suggest that using higherthan-conventional doses of ARB treatment may afford renoprotection without producing greater BP reductions or affecting the safety/tolerability profile, compared with established doses. ${ }^{126-128}$ Significant reductions in albuminuria, compared with conventional antihypertensive dosing, have been reported for irbesartan $900 \mathrm{mg} /$ day compared with $300 \mathrm{mg} /$ day $^{126}$ and valsartan $640 \mathrm{mg} /$ day compared with $160 \mathrm{mg} /$ day $^{127}$ (both studies in patients with T2D and microalbuminuria, the former of 8 weeks and the latter of 30 weeks' duration) and most recently for candesartan $128 \mathrm{mg}$ /day compared with $16 \mathrm{mg} /$ day (in patients with diabetes-related or diabetes-unrelated persistent proteinuria). ${ }^{128}$ Currently, no further studies evaluate the longterm effects of supramaximal doses of ARBs on organ protection or CV morbidity/mortality. As the ARBs' life cycle nears the end, no long-term studies are planned.

\section{CONCLUSION}

When treating patients, clinicians should design a treatment plan that takes into consideration all comorbidities/risk factors and choose the ARB that is proven effective, based on RCTs, in their management. This strategy could facilitate the clinicians' task of managing complicated patients, together with providing cost savings and better patient compliance.

\section{ACKNOWLEDGMENTS}

The preparation of this manuscript was made possible by funding from Novartis Pharmaceuticals Corporation. Laurie A. Orloski, PharmD, RPh, of Oxford PharmaGenesis Inc., drafted the manuscript under the guidance of Dr. Siragy. Dr. Siragy reviewed the first draft and revised it critically for important intellectual content. Dr. Siragy is supported by research grants from the National Institutes of Health, National Heart, Lung, and Blood Institute, and Novartis Pharmaceuticals Corporation.

\section{REFERENCES}

1. Chobanian AV, Bakris GL, Black HR, et al. Seventh Report of the Joint National Committee on Prevention, Detection, Evaluation, and Treatment of High Blood Pressure. Hypertension. 2003;42:1206-1252.

2. Wong ND, Lopez VA, L'Italien G, et al. Inadequate control of hypertension in US adults with cardiovascular disease comorbidities in 2003-2004. Arch Intern Med. 2007;167:2431-2436. 
3. Saltzman HE, Sharma K, Mather PJ, et al. Renal dysfunction in heart failure patients: what is the evidence? Heart Fail Rev. 2007;12:37-47.

4. Siragy HM. Angiotensin receptor blockers: how important is selectivity? Am J Hypertens. 2002;15:1006-1014.

5. Victor RG. Pathophysiology of target-organ disease: does angiotensin II remain the key? J Clin Hypertens (Greenwich). 2007;9(suppl 4):4-10.

6. Siragy HM. Evidence for benefits of angiotensin receptor blockade beyond blood pressure control. Curr Hypertens Rep. 2008;10:261-267.

7. Volpe M, Ruilope LM, McInnes GT, Waeber B, Weber MA. Angiotensin-II receptor blockers: benefits beyond blood pressure reduction? J Hum Hypertens. 2005;19:331-339.

8. Cozaar (losartan potassium) Tablets [prescribing information]. 2006. Merck \& Co., Inc, Whitehouse Station, NJ.

9. Diovan (valsartan) Tablets [prescribing information]. 2008. Novartis Pharmaceuticals Corporation, East Hanover, NJ.

10. Atacand (candesartan cilexetil) Tablets [prescribing information]. 2009. AstraZeneca LP, Wilmington, DE.

11. Avapro (irbesartan) Tablets [prescribing information]. 2007. Bristol Myers Squibb SanofiSynthelabo Partnership, New York, NY.

12. Micardis (telmisartan) Tablets [prescribing information]. 2009. Boehringer Ingelheim Pharmaceuticals, Inc., Ridgefield, CT.

13. Teveten (eprosartan mesylate) Tablets [prescribing information]. 2007. Abbott Laboratories, North Chicago, IL.

14. Benicar (olmesartan medoxomil) Tablets [prescribing information]. 2009. Daiichi Sankyo, Inc., Parsippany, NJ.

15. Al Khalaf MM, Thalib L, Doi SA. Cardiovascular outcomes in high-risk patients without heart failure treated with ARBs: a systematic review and meta-analysis. Am J Cardiovasc Drugs. 2009;9:2943.

16. Wang JG, Li Y, Franklin SS, Safar M. Prevention of stroke and myocardial infarction by amlodipine and angiotensin receptor blockers: a quantitative overview. Hypertension. 2007;50:181-188.
17. Kunz R, Friedrich C, Wolbers M, Mann JF. Metaanalysis: effect of monotherapy and combination therapy with inhibitors of the renin angiotensin system on proteinuria in renal disease. Ann Intern Med. 2008;148:30-48.

18. Sarafidis PA, Stafylas PC, Kanaki AI, Lasaridis AN. Effects of renin-angiotensin system blockers on renal outcomes and all-cause mortality in patients with diabetic nephropathy: an updated metaanalysis. Am J Hypertens. 2008;21:922-929.

19. Jennings DL, Kalus JS, Coleman CI, Manierski C, Yee J. Combination therapy with an ACE inhibitor and an angiotensin receptor blocker for diabetic nephropathy: a meta-analysis. Diabet Med. 2007;24:486-493.

20. Lakhdar R, Al-Mallah MH, Lanfear DE. Safety and tolerability of angiotensin-converting enzyme inhibitor versus the combination of angiotensinconverting enzyme inhibitor and angiotensin receptor blocker in patients with left ventricular dysfunction: a systematic review and meta-analysis of randomized controlled trials. J Card Fail. 2008;14:181-188.

21. Fagard RH, Celis H, Thijs L, Wouters S. Regression of left ventricular mass by antihypertensive treatment: a meta-analysis of randomized comparative studies. Hypertension. 2009;54:1084-1091.

22. Dimopoulos K, Salukhe TV, Coats AJ, et al. Metaanalyses of mortality and morbidity effects of an angiotensin receptor blocker in patients with chronic heart failure already receiving an ACE inhibitor (alone or with a beta-blocker). Int J Cardiol. 2004;93:105-111.

23. Elmfeldt D, Olofsson B, Meredith P. The relationships between dose and antihypertensive effect of four AT1-receptor blockers. Differences in potency and efficacy. Blood Press. 2002;11:293301.

24. Uchiyama-Tanaka Y, Mori Y, Kishimoto N, et al. Comparison of the effects of quinapril and losartan on carotid artery intima-media thickness in patients with mild-to-moderate arterial hypertension. Kidney Blood Press Res. 2005;28:111-116.

25. Flammer AJ, Hermann F, Wiesli P, et al. Effect of losartan, compared with atenolol, on endothelial function and oxidative stress in patients with type 2 diabetes and hypertension. J Hypertens. 2007;25:785-791.

26. Ichihara A, Hayashi M, Kaneshiro $\mathrm{Y}$, et al. Low doses of losartan and trandolapril improve arterial 
stiffness in hemodialysis patients. Am J Kidney Dis. 2005;45:866-874.

27. Park JB, Intengan HD, Schiffrin EL. Reduction of resistance artery stiffness by treatment with the AT(1)-receptor antagonist losartan in essential hypertension. J Renin Angiotensin Aldosterone Syst. 2000;1:40-45.

28. Rehman A, Ismail SB, Naing L, Roshan TM, Rahman AR. Reduction in arterial stiffness with angiotensin II antagonism and converting enzyme inhibition. A comparative study among Malay hypertensive subjects with a known genetic profile. Am J Hypertens. 2007;20:184-189.

29. Dahlöf B, Devereux RB, Kjeldsen SE, et al. Cardiovascular morbidity and mortality in the Losartan Intervention For Endpoint Reduction in Hypertension study (LIFE): a randomised trial against atenolol. Lancet. 2002;359:995-1003.

30. Kjeldsen SE, Dahlof B, Devereux RB, et al. Effects of losartan on cardiovascular morbidity and mortality in patients with isolated systolic hypertension and left ventricular hypertrophy: a Losartan Intervention for Endpoint Reduction (LIFE) substudy. JAMA. 2002;288:1491-1498.

31. Okin PM, Devereux RB, Jern S, et al. Regression of electrocardiographic left ventricular hypertrophy by losartan versus atenolol: The Losartan Intervention for Endpoint reduction in Hypertension (LIFE) study. Circulation. 2003;108:684-690.

32. Devereux RB, Dahlöf B, Gerdts E, et al. Regression of hypertensive left ventricular hypertrophy by losartan compared with atenolol: the Losartan Intervention for Endpoint Reduction in Hypertension (LIFE) trial. Circulation. 2004;110:1456-1462.

33. Dickstein K, Kjekshus J. Effects of losartan and captopril on mortality and morbidity in highrisk patients after acute myocardial infarction: the OPTIMAAL randomised trial. Optimal Trial in Myocardial Infarction with Angiotensin II Antagonist Losartan. Lancet. 2002;360:752-760.

34. Kizer JR, Dahlöf B, Kjeldsen SE, et al. Stroke reduction in hypertensive adults with cardiac hypertrophy randomized to losartan versus atenolol: the Losartan Intervention For Endpoint Reduction in Hypertension study. Hypertension. 2005;45:46-52.

35. Pitt B, Segal R, Martinez FA, et al. Randomised trial of losartan versus captopril in patients over 65 with heart failure (Evaluation of Losartan in the Elderly Study, ELITE). Lancet. 1997;349:747-752.

36. Konstam MA, Patten RD, Thomas I, et al. Effects of losartan and captopril on left ventricular volumes in elderly patients with heart failure: results of the ELITE ventricular function substudy. Am Heart J. 2000;139:1081-1087.

37. Pitt B, Poole-Wilson PA, Segal R, et al. Effect of losartan compared with captopril on mortality in patients with symptomatic heart failure: randomised trial - the Losartan Heart Failure Survival Study ELITE II. Lancet. 2000;355:15821587.

38. Wachtell K, Lehto M, Gerdts E, et al. Angiotensin II receptor blockade reduces new-onset atrial fibrillation and subsequent stroke compared to atenolol: the Losartan Intervention For Endpoint Reduction in Hypertension (LIFE) study. J Am Coll Cardiol. 2005;45:712-719.

39. Brenner BM, Cooper ME, de Zeeuw D, et al. Effects of losartan on renal and cardiovascular outcomes in patients with type 2 diabetes and nephropathy. N Engl J Med. 2001;345:861-869.

40. Iino $\mathrm{Y}$, Hayashi $\mathrm{M}$, Kawamura $\mathrm{T}$, et al. Renoprotective effect of losartan in comparison to amlodipine in patients with chronic kidney disease and hypertension - a report of the Japanese Losartan Therapy Intended for the Global Renal Protection in Hypertensive Patients (JLIGHT) study. Hypertens Res. 2004;27:21-30.

41. Hou FF, Xie D, Zhang X, et al. Renoprotection of Optimal Antiproteinuric Doses (ROAD) study: a randomized controlled study of benazepril and losartan in chronic renal insufficiency. J Am Soc Nephrol. 2007;18:1889-1898.

42. Karalliedde J, Smith A, DeAngelis L, et al. Valsartan improves arterial stiffness in type 2 diabetes independently of blood pressure lowering. Hypertension. 2008;51:1617-1623.

43. Serebruany VL, Pokov AN, Malinin AI, et al. Valsartan inhibits platelet activity at different doses in mild to moderate hypertensives: Valsartan Inhibits Platelets (VIP) trial. Am Heart J. 2006;151:92-99.

44. Anan F, Takahashi N, Ooie T, et al. Effects of valsartan and perindopril combination therapy on left ventricular hypertrophy and aortic arterial stiffness in patients with essential hypertension. Eur J Clin Pharmacol. 2005;61:353-359. 
45. Cuocolo A, Storto G, Izzo R, et al. Effects of valsartan on left ventricular diastolic function in patients with mild or moderate essential hypertension: comparison with enalapril. J Hypertens. 1999;17:1759-1766.

46. Thürmann PA, Kenedi P, Schmidt A, Harder S, Rietbrock N. Influence of the angiotensin II antagonist valsartan on left ventricular hypertrophy in patients with essential hypertension. Circulation. 1998;98:2037-2042.

47. Yasunari $\mathrm{K}$, Maeda $\mathrm{K}$, Watanabe $\mathrm{T}$, et al. Comparative effects of valsartan versus amlodipine on left ventricular mass and reactive oxygen species formation by monocytes in hypertensive patients with left ventricular hypertrophy. J Am Coll Cardiol. 2004;43:2116-2123.

48. Pfeffer MA, McMurray JJ, Velazquez EJ, et al. Valsartan, captopril, or both in myocardial infarction complicated by heart failure, left ventricular dysfunction, or both. N Engl J Med. 2003;349:1893-1906.

49. Solomon SD, Skali H, Anavekar NS, et al. Changes in ventricular size and function in patients treated with valsartan, captopril, or both after myocardial infarction. Circulation. 2005;111:3411-3419.

50. Suzuki H, Geshi E, Nanjyo S, et al. Inhibitory effect of valsartan against progression of left ventricular dysfunction after myocardial infarction: T-VENTURE study. Circ J. 2009;73:918-924.

51. Mochizuki S, Dahlof B, Shimizu M, et al. Valsartan in a Japanese population with hypertension and other cardiovascular disease (Jikei Heart Study): a randomised, open-label, blinded endpoint morbidity-mortality study. Lancet. 2007;369:14311439.

52. Sawada T, Yamada $H$, Dahlöf B, Matsubara $H$. Effects of valsartan on morbidity and mortality in uncontrolled hypertensive patients with high cardiovascular risks: KYOTO HEART Study. Eur Heart J. 2009;30:2461-2469.

53. Cohn JN, Tognoni G. A randomized trial of the angiotensin-receptor blocker valsartan in chronic heart failure. N Engl J Med. 2001;345:1667-1675.

54. Wong M, Staszewsky L, Latini R, et al. Valsartan benefits left ventricular structure and function in heart failure: Val-HeFT echocardiographic study. J Am Coll Cardiol. 2002;40:970-975.

55. Disertori M, Latini R, Barlera S, et al. Valsartan for prevention of recurrent atrial fibrillation. N Engl J Med. 2009;360:1606-1617.
56. Maggioni AP, Latini R, Carson PE, et al. Valsartan reduces the incidence of atrial fibrillation in patients with heart failure: results from the Valsartan Heart Failure Trial (Val-HeFT). Am Heart J. 2005;149:548-557.

57. Viberti G, Wheeldon NM. Microalbuminuria reduction with valsartan in patients with type 2 diabetes mellitus: a blood pressure-independent effect. Circulation. 2002;106:672-678.

58. Uzu T, Sawaguchi M, Maegawa H, Kashiwagi A. Reduction of microalbuminuria in patients with type 2 diabetes: the Shiga Microalbuminuria Reduction Trial (SMART). Diabetes Care. 2007;30:1581-1583.

59. Menne J, Farsang C, Deák L, et al. Valsartan in combination with lisinopril versus the respective high dose monotherapies in hypertensive patients with microalbuminuria: the VALERIA trial. J Hypertens. 2008;26:1860-1867.

60. Li PK, Leung CB, Chow KM, et al. Hong Kong Study Using Valsartan in IgA Nephropathy (HKVIN): a double-blind, randomized, placebo-controlled study. Am J Kidney Dis. 2006;47:751-760.

61. Rosei EA, Rizzoni D, Muiesan ML, et al. Effects of candesartan cilexetil and enalapril on inflammatory markers of atherosclerosis in hypertensive patients with non-insulin-dependent diabetes mellitus. J Hypertens. 2005;23:435-444.

62. Cuspidi C, Muiesan ML, Valagussa L, et al. Comparative effects of candesartan and enalapril on left ventricular hypertrophy in patients with essential hypertension: the candesartan assessment in the treatment of cardiac hypertrophy (CATCH) study. J Hypertens. 2002;20:2293-2300.

63. Ogihara T, Fujimoto A, Nakao K, Saruta T. ARB candesartan and CCB amlodipine in hypertensive patients: the CASE-J trial. Expert Rev Cardiovasc Ther. 2008;6:1195-1201.

64. Suzuki H, Kanno Y. Effects of candesartan on cardiovascular outcomes in Japanese hypertensive patients. Hypertens Res. 2005;28:307-314.

65. Lithell H, Hansson L, Skoog I, et al. The Study on Cognition and Prognosis in the Elderly (SCOPE): principal results of a randomized double-blind intervention trial. J Hypertens. 2003;21:875-886.

66. Papademetriou V, Farsang C, Elmfeldt D, et al. Stroke prevention with the angiotensin II type 1-receptor blocker candesartan in elderly patients with isolated systolic hypertension: the 
Study on Cognition and Prognosis in the Elderly (SCOPE). J Am Coll Cardiol. 2004;44:1175-1180.

67. McKelvie RS, Yusuf S, Pericak D, et al. Comparison of candesartan, enalapril, and their combination in congestive heart failure: randomized evaluation of strategies for left ventricular dysfunction (RESOLVD) pilot study. The RESOLVD Pilot Study Investigators. Circulation. 1999;100:1056-1064.

68. Pfeffer MA, Swedberg K, Granger CB, et al. Effects of candesartan on mortality and morbidity in patients with chronic heart failure: the CHARMOverall programme. Lancet. 2003;362:759-766.

69. Solomon SD, Wang D, Finn P, et al. Effect of candesartan on cause-specific mortality in heart failure patients: the Candesartan in Heart Failure Assessment of Reduction in Mortality and Morbidity (CHARM) program. Circulation. 2004;110:2180-2183.

70. O'Meara E, Solomon S, McMurray J, et al. Effect of candesartan on New York Heart Association functional class. Results of the Candesartan in Heart Failure: Assessment of Reduction in Mortality and Morbidity (CHARM) programme. Eur Heart J. 2004;25:1920-1926.

71. Young JB, Dunlap ME, Pfeffer MA, et al. Mortality and morbidity reduction with candesartan in patients with chronic heart failure and left ventricular systolic dysfunction: results of the CHARM low-left ventricular ejection fraction trials. Circulation. 2004;110:2618-2626.

72. McMurray JJ, Ostergren J, Swedberg K, et al. Effects of candesartan in patients with chronic heart failure and reduced left-ventricular systolic function taking angiotensin-converting-enzyme inhibitors: the CHARM-Added trial. Lancet. 2003;362:767-771.

73. Granger CB, McMurray JJ, Yusuf S, et al. Effects of candesartan in patients with chronic heart failure and reduced left-ventricular systolic function intolerant to angiotensin-converting-enzyme inhibitors: the CHARM-Alternative trial. Lancet. 2003;362:772-776.

74. Yusuf S, Pfeffer MA, Swedberg K, et al. Effects of candesartan in patients with chronic heart failure and preserved left-ventricular ejection fraction: the CHARM-Preserved trial. Lancet. 2003;362:777-781.

75. Tveit A, Grundvold I, Olufsen M, et al. Candesartan in the prevention of relapsing atrial fibrillation. Int J Cardiol. 2007;120:85-91.
76. Bilous R, Chaturvedi N, Sjolie AK, et al. Effect of candesartan on microalbuminuria and albumin excretion rate in diabetes: three randomized trials. Ann Intern Med. 2009;151:11-14.

77. Mörtsell D, Malmqvist K, Held C, Kahan T. Irbesartan reduces common carotid artery intimamedia thickness in hypertensive patients when compared with atenolol: the Swedish Irbesartan Left Ventricular Hypertrophy Investigation versus Atenolol (SILVHIA) study. J Intern Med. 2007;261:472-479.

78. Morawietz H, Erbs S, Holtz J, et al. Endothelial Protection, AT1 Blockade and CholesterolDependent Oxidative Stress: the EPAS trial. Circulation. 2006;114(1 suppl):I296-I301.

79. Sola S, Mir MQ, Cheema FA, et al. Irbesartan and lipoic acid improve endothelial function and reduce markers of inflammation in the metabolic syndrome: results of the Irbesartan and Lipoic Acid in Endothelial Dysfunction (ISLAND) study. Circulation. 2005;111:343-348.

80. Malmqvist K, Kahan T, Edner M, et al. Regression of left ventricular hypertrophy in human hypertension with irbesartan. J Hypertens. 2001;19:1167-1176.

81. Malmqvist $\mathrm{K}$, Öhman KP, Lind L, Nyström F, Kahan T. Long-term effects of irbesartan and atenolol on the renin-angiotensin-aldosterone system in human primary hypertension: the Swedish Irbesartan Left Ventricular Hypertrophy Investigation versus Atenolol (SILVHIA). J Cardiovasc Pharmacol. 2003;42:719-726.

82. Schneider MP, Klingbeil AU, Delles C, et al. Effect of irbesartan versus atenolol on left ventricular mass and voltage: results of the CardioVascular Irbesartan Project. Hypertension. 2004;44:61-66.

83. Massie BM, Carson PE, McMurray JJ, et al. Irbesartan in patients with heart failure and preserved ejection fraction. N Engl J Med. 2008;359:2456-2467.

84. Guntekin U, Gunes Y, Tuncer M, Simsek H, Gunes A. Comparison of the effects of quinapril and irbesartan on P-wave dispersion in hypertensive patients. Adv Ther. 2008;25:775-786.

85. Madrid AH, Bueno MG, Rebollo JM, et al. Use of irbesartan to maintain sinus rhythm in patients with long-lasting persistent atrial fibrillation: a prospective and randomized study. Circulation. 2002;106:331-336.

86. Lewis EJ, Hunsicker LG, Clarke WR, et al. Renoprotective effect of the angiotensin-receptor 
antagonist irbesartan in patients with nephropathy due to type 2 diabetes. N Engl J Med. 2001;345:851860 .

87. Parving $\mathrm{HH}$, Lehnert $\mathrm{H}$, Bröchner-Mortensen J, et al. The effect of irbesartan on the development of diabetic nephropathy in patients with type 2 diabetes. N Engl J Med. 2001;345:870-878.

88. Bakris GL, Ruilope L, Locatelli F, et al. Treatment of microalbuminuria in hypertensive subjects with elevated cardiovascular risk: results of the IMPROVE trial. Kidney Int. 2007;72:879-885.

89. Asmar R, Gosse P, Topouchian J, et al. Effects of telmisartan on arterial stiffness in type 2 diabetes patients with essential hypertension. J Renin Angiotensin Aldosterone Syst. 2002;3:176-180.

90. Jung AD, Kim W, Park SH, et al. The effect of telmisartan on endothelial function and arterial stiffness in patients with essential hypertension. Korean Circ J. 2009;39:180-184.

91. Verdecchia P, Sleight P, Mancia G, et al. Effects of telmisartan, ramipril, and their combination on left ventricular hypertrophy in individuals at high vascular risk in the Ongoing Telmisartan Alone and in Combination With Ramipril Global Endpoint trial and the Telmisartan Randomized Assessment Study in ACE Intolerant Subjects With Cardiovascular Disease. Circulation. 2009; 120:1380-1389.

92. Yusuf S, Teo K, Anderson C, et al. Effects of the angiotensin-receptor blocker telmisartan on cardiovascular events in high-risk patients intolerant to angiotensin-converting enzyme inhibitors: a randomised controlled trial. Lancet. 2008;372:1174-1183.

93. Yusuf S, Diener HC, Sacco RL, et al. Telmisartan to prevent recurrent stroke and cardiovascular events. N Engl J Med. 2008;359:1225-1237.

94. Dunselman PH. Effects of the replacement of the angiotensin converting enzyme inhibitor enalapril by the angiotensin II receptor blocker telmisartan in patients with congestive heart failure. The Replacement of Angiotensin Converting Enzyme Inhibition (REPLACE) investigators. Int J Cardiol. 2001;77:131-138.

95. Celik T, Iyisoy A, Kursaklioglu $H$, et al. The comparative effects of telmisartan and ramipril on P-wave dispersion in hypertensive patients: a randomized clinical study. Clin Cardiol. 2005;28:298-302.
96. Makino H, Haneda M, Babazono T, et al. Prevention of transition from incipient to overt nephropathy with telmisartan in patients with type 2 diabetes. Diabetes Care. 2007;30:1577-1578.

97. Mann JF, Schmieder RE, Dyal L, et al. Effect of telmisartan on renal outcomes: a randomized trial. Ann Intern Med. 2009;151:1-10, W1-W2.

98. Mann JF, Schmieder RE, McQueen M, et al. Renal outcomes with telmisartan, ramipril, or both, in people at high vascular risk (the ONTARGET study): a multicentre, randomised, double-blind, controlled trial. Lancet. 2008;372:547-553.

99. Barnett A. Preventing renal complications in type 2 diabetes: results of the diabetics exposed to telmisartan and enalapril trial. J Am Soc Nephrol. 2006;17:S132-S135.

100. Leu HB, Charng MJ, Ding PY. A double blind randomized trial to compare the effects of eprosartan and enalapril on blood pressure, platelets, and endothelium function in patients with essential hypertension. Jpn Heart J. 2004;45:623-635.

101. Fliser D, Buchholz K, Haller H. Antiinflammatory effects of angiotensin II subtype 1 receptor blockade in hypertensive patients with microinflammation. Circulation. 2004;110:1103-1107.

102. Diamond JA, Gharavi A, Roychoudhury D, et al. Effect of long-term eprosartan versus enalapril antihypertensive therapy on left ventricular mass and coronary flow reserve in stage I-II hypertension. Eprosartan Study Group. Curr Med Res Opin. 1999;15:1-8.

103. Rosendorff C, Dubiel $\mathrm{R}, \mathrm{Xu} \mathrm{J}$, Chavanu KJ. Comparison of olmesartan medoxomil versus amlodipine besylate on regression of ventricular and vascular hypertrophy. Am J Cardiol. 2009;104:359-365.

104. Schrader J, Luders S, Kulschewski A, et al. Morbidity and Mortality After Stroke, Eprosartan Compared with Nitrendipine for Secondary Prevention: principal results of a prospective randomized controlled study (MOSES). Stroke. 2005;36:12181226.

105. Murdoch DR, McDonagh TA, Farmer R, et al. ADEPT: addition of the AT1 receptor antagonist eprosartan to ACE inhibitor therapy in chronic heart failure trial: hemodynamic and neurohormonal effects. Am Heart J. 2001;141:800-807.

106. Ikeda H, Minamikawa J, Nakamura Y, et al. Comparison of effects of amlodipine and 
angiotensin receptor blockers on the intimamedia thickness of carotid arterial wall (AAA study: amlodipine vs. ARB in atherosclerosis study). Diabetes Res Clin Pract. 2009;83:50-53.

107. Baguet JP, Asmar R, Valensi P, Nisse-Durgeat S, Mallion JM. Effects of candesartan cilexetil on carotid remodeling in hypertensive diabetic patients: the MITEC study. Vasc Health Risk Manag. 2009;5:175-183.

108. Wachtell K, Bella JN, Rokkedal J, et al. Change in diastolic left ventricular filling after one year of antihypertensive treatment: The Losartan Intervention For Endpoint Reduction in Hypertension (LIFE) Study. Circulation. 2002;105:1071-1076.

109. Devereux RB, Palmieri V, Liu JE, et al. Progressive hypertrophy regression with sustained pressure reduction in hypertension: the Losartan Intervention For Endpoint Reduction study. J Hypertens. 2002;20:1445-1450.

110. Picca M, Agozzino F, Pelosi G. Effects of losartan and valsartan on left ventricular hypertrophy and function in essential hypertension. Adv Ther. 2004;21:76-86.

111. Devereux RB, Dahlof B, Kjeldsen SE, et al. Effects of losartan or atenolol in hypertensive patients without clinically evident vascular disease: a substudy of the LIFE randomized trial. Ann Intern Med. 2003;139:169-177.

112. Konstam MA, Neaton JD, Poole-Wilson PA, et al. Comparison of losartan and captopril on heart failure-related outcomes and symptoms from the losartan heart failure survival study (ELITE II). Am Heart J. 2005;150:123-131.

113. Wong M, Staszewsky L, Latini R, et al. Severity of left ventricular remodeling defines outcomes and response to therapy in heart failure: Valsartan heart failure trial (Val-HeFT) echocardiographic data. J Am Coll Cardiol. 2004;43:2022-2027.

114. Okin PM, Wachtell K, Devereux RB, et al. Regression of electrocardiographic left ventricular hypertrophy and decreased incidence of new-onset atrial fibrillation in patients with hypertension. JAMA. 2006;296:1242-1248.

115. Yin Y, Dalal D, Liu Z, et al. Prospective randomized study comparing amiodarone vs. amiodarone plus losartan vs. amiodarone plus perindopril for the prevention of atrial fibrillation recurrence in patients with lone paroxysmal atrial fibrillation. Eur Heart J. 2006;27:1841-1846.
116. Bakris G, Burgess E, Weir M, Davidai G, Koval S. Telmisartan is more effective than losartan in reducing proteinuria in patients with diabetic nephropathy. Kidney Int. 2008;74:364-369.

117. Galle J, Schwedhelm E, Pinnetti S, Böger RH, Wanner C. Antiproteinuric effects of angiotensin receptor blockers: telmisartan versus valsartan in hypertensive patients with type 2 diabetes mellitus and overt nephropathy. Nephrol Dial Transplant. 2008;23:3174-3183.

118. Matsuda H, Hayashi K, Homma K, et al. Differing anti-proteinuric action of candesartan and losartan in chronic renal disease. Hypertens Res. 2003;26:875-880.

119. Rayner BL, Trinder YA, Baines D, Isaacs S, Opie LH. Effect of losartan versus candesartan on uric acid, renal function, and fibrinogen in patients with hypertension and hyperuricemia associated with diuretics. Am J Hypertens. 2006;19:208-213.

120. Elliott WJ, Meyer PM. Incident diabetes in clinical trials of antihypertensive drugs: a network metaanalysis. Lancet. 2007;369:201-207.

121. Califf RM, Boolell M, Haffner SM, et al. Prevention of diabetes and cardiovascular disease in patients with impaired glucose tolerance: rationale and design of the Nateglinide And Valsartan in Impaired Glucose Tolerance Outcomes Research (NAVIGATOR) Trial. Am Heart J. 2008;156:623632.

122. Holman RR, Haffner SM, McMurray JJ, et al. Effect of nateglinide on the incidence of diabetes and cardiovascular events. $\mathrm{N}$ Engl $\mathrm{J}$ Med. 2010;362:1463-1476.

123. McMurray JJ, Holman RR, Haffner SM, et al. Effect of valsartan on the incidence of diabetes and cardiovascular events. $\mathrm{N}$ Engl J Med. 2010;362:1477-1490.

124. Signorovitch J, Zhang J, Wu EQ, et al. Economic impact of switching from valsartan to other angiotensin receptor blockers in patients with hypertension. Curr Med Res Opin. 2010;26:849860.

125. Konstam MA, Neaton JD, Dickstein K, et al. Effects of high-dose versus low-dose losartan on clinical outcomes in patients with heart failure (HEAAL study): a randomised, double-blind trial. Lancet. 2009;374:1840-1848.

126. Rossing K, Schjoedt KJ, Jensen BR, Boomsma F, Parving $\mathrm{HH}$. Enhanced renoprotective effects of 
ultrahigh doses of irbesartan in patients with type 2 diabetes and microalbuminuria. Kidney Int. 2005;68:1190-1198.

127. Hollenberg NK, Parving HH, Viberti G, et al. Albuminuria response to very high-dose valsartan in type 2 diabetes mellitus. J Hypertens. 2007;25:1921-1926.

128. Burgess E, Muirhead N, Rene de Cotret P, et al. Supramaximal dose of candesartan in proteinuric renal disease. J Am Soc Nephrol. 2009;20:893-900.

\section{APPENDIX: LIST OF CLINICAL TRIAL ACRONYMS}

\begin{tabular}{|c|c|}
\hline AAA & Amlodipine vs. ARB in Atherosclerosis \\
\hline ADEPT & Addition of the $\mathrm{AT}_{1}$ Receptor Antagonist Eprosartan to ACE Inhibitor Therapy in Chronic Heart Failure \\
\hline AMADEO & Telmisartan vs. Losartan in Hypertensive Type 2 Diabetic Patients with Overt Nephropathy \\
\hline CAPRAF & Candesartan in the Prevention of Relapsing Atrial Fibrillation \\
\hline CASE-J & Candesartan Antihypertensive Survival Evaluation in Japan \\
\hline CATCH & Italian Candesartan Assessment in the Treatment of Cardiac Hypertrophy \\
\hline CENTRO & Candesartan on Atherosclerotic Risk Factors \\
\hline CHARM & Candesartan in Heart Failure Assessment of Reduction in Mortality and Morbidity \\
\hline CVIP & Cardiovascular Irbesartan Project \\
\hline DETAIL & Diabetics Exposed to Telmisartan and Enalapril \\
\hline DIRECT & Diabetic Retinopathy Candesartan Trials \\
\hline E-COST & Efficacy of Candesartan on Outcome in Saitama Trial \\
\hline ELITE & Evaluation of Losartan in the Elderly \\
\hline EPAS & Endothelial Protection, $\mathrm{AT}_{1}$ Blockade and Cholesterol-Dependent Oxidative Stress \\
\hline EUTOPIA & European Trial on Olmesartan and Pravastatin in Inflammation and Atherosclerosis \\
\hline GISSI-AF & Gruppo Italiano per lo Studio della Sopravvivenza nell'Infarto Miocardio-Atrial Fibrillation \\
\hline HEAAL & Heart Failure Endpoint Evaluation of Angiotensin II Antagonist Losartan \\
\hline HKVIN & Hong Kong Study Using Valsartan in IgA Nephropathy \\
\hline IDNT & Irbesartan Diabetic Nephropathy Trial \\
\hline IMPROVE & Irbesartan in the Management of Proteinuric Patients at High Risk of Vascular Events \\
\hline INNOVATION & Incipient to Overt: Angiotensin II Blocker, Telmisartan, Investigation on Type 2 Diabetic Nephropathy \\
\hline I-PRESERVE & Irbesartan in Heart Failure with Preserved Ejection Fraction \\
\hline IRMA- & Irbesartan in Patients with Type 2 Diabetes and Microalbuminuria \\
\hline ISLAND & Irbesartan and Lipoic Acid in Endothelial Dysfunction \\
\hline JLIGHT & Japanese Losartan Therapy Intended for the Global Renal Protection in Hypertensive Patients \\
\hline LIFE & Losartan Intervention for Endpoint Reduction \\
\hline MARVAL & Microalbuminuria Reduction with Valsartan \\
\hline MITEC & Media Intima Thickness Evaluation with Candesartan Cilexetil \\
\hline MOSES & Morbidity and Mortality after Stroke, Eprosartan Compared with Nitrendipine for Secondary Prevention \\
\hline
\end{tabular}




\begin{tabular}{ll}
\hline NAVIGATOR & Nateglinide and Valsartan in Impaired Glucose Tolerance Outcomes Research \\
\hline ONTARGET & Ongoing Telmisartan Alone and in Combination with Ramipril Global Endpoint Trial \\
\hline PRTIMAAL & Optimal Trial in Myocardial Infarction with the Angiotensin II Antagonist Losartan \\
\hline RENAAL & Prevention Regimen for Effectively Avoiding Second Strokes \\
\hline REPLACE & Replaction of Endpoints in NIDDM with the Angiotensin II Antagonist Losartan \\
\hline RESOLVD & Randomized Evaluation of Strategies for Left Ventricular Dysfunction \\
\hline ROAD & Renoprotection of Optimal Antiproteinuric Doses \\
\hline SCOPE & Study on Cognition and Prognosis in the Elderly \\
\hline SILVHIA & Swedish Irbesartan Left Ventricular Hypertrophy Versus Atenolol \\
\hline SMART & Shiga Microalbuminuria Reduction Trial \\
\hline TRANSCEND & Telmisartan Randomized Assessment Study in ACE Intolerant Subjects with Cardiovascular Disease \\
\hline T-VENTURE & Inhibitory Effect of Valsartan against Progression of Left Ventricular Dysfunction after Myocardial \\
\hline VALERIA & Infarction \\
\hline Val-HeFT & Valsartan in Combination with Lisinopril in Hypertensive Patients with Microalbuminuria \\
\hline VALIANT & Valsartan Heart Failure Trial \\
\hline VIP & Valsartan in Acute Myocardial Infarction \\
\hline VIVALDI & Valsartan Inhibits Platelets \\
\hline
\end{tabular}

